\title{
Air Pollution Transport in an Alpine Valley: Results From Airborne and Ground-Based Observations
}

\author{
A. Gohm - F. Harnisch - J. Vergeiner - F. Obleitner • \\ R. Schnitzhofer • A. Hansel • A. Fix • B. Neininger • \\ S. Emeis • K. Schäfer
}

Received: 21 October 2008 / Accepted: 3 March 2009

(C) Springer Science+Business Media B.V. 2009

\begin{abstract}
An observational dataset from a wintertime field campaign in the Inn Valley, Austria, is analysed in order to study mechanisms of air pollution transport in an Alpine valley. The results illustrate three types of mechanisms: transport by a density current, backand-forth transport by valley winds, and transport by slope winds. The first type is associated with an air mass difference along the valley. Cooler air located in the lower part of the valley behaves like a density current and produces the advection of pollutants by upvalley winds. In the second type, strong horizontal gradients in pollution concentrations exist close to ground. Multiple wind reversals result in a back-and-forth transport of pollutants by weak valley winds. In the third type, upslope winds during daytime decrease low-level pollution concentrations and cause the formation of elevated pollution layers.
\end{abstract}

Keywords Aerosols $\cdot$ ALPNAP $\cdot$ Foehn $\cdot$ Lidar $\cdot$ Local winds $\cdot \mathrm{NO}_{x} \cdot$ Particulate matter

\section{Introduction}

Local flows play an important role in the dispersion of air pollutants in mountainous terrain. Dynamically or thermally forced winds may enhance or suppress dispersion relative to the

\footnotetext{
A. Gohm $(\varangle) \cdot$ J. Vergeiner $\cdot$ F. Obleitner

Institute of Meteorology and Geophysics, University of Innsbruck, Innrain 52, 6020 Innsbruck, Austria

e-mail: alexander.gohm@uibk.ac.at

F. Harnisch · A. Fix

Institut für Physik der Atmosphäre, DLR, Oberpfaffenhofen, Germany

R. Schnitzhofer · A. Hansel

Institute for Ion Physics and Applied Physics, University of Innsbruck, Innsbruck, Austria

B. Neininger

MetAir AG, Menzingen, Switzerland

S. Emeis - K. Schäfer

IMK-IFU, Forschungszentrum Karlsruhe, Garmisch-Partenkirchen, Germany
} 
surrounding plains (Whiteman 2000). Valleys are affected by processes such as flow channelling, sheltering, cold-air pooling, drainage, slope flows, and plume impingement on higher terrain (Hanna and Strimaitis 1990; Whiteman 2000). Our study attempts to elucidate a small selection of these pollution transport processes based on high-resolution, three-dimensional airborne and ground-based observations. Our goal is to draw a fine-scale picture of these processes by focusing on the hibernal atmosphere of the Inn Valley, Austria.

The importance of local flows in complex terrain on pollution dispersion has been documented in several previous studies. Diurnal valley winds, driven by daytime heating and nocturnal cooling of the boundary layer, are able to carry pollutants upvalley during the day (McKendry et al. 1998) and downvalley during the night (Banta et al. 1997), respectively. These pollutants may originate from the surrounding plains (Furger et al. 2000) or may be emitted inside the valley. The valley wind circulation can be significantly influenced and modified by the synoptic-scale flow above the mountains (Schmidli et al. 2009), while the interaction with upper-level winds may affect the pollution transport in the valley-wind layer below (Prévôt et al. 2000). Flow from tributaries into the main valley may lead to complex flow structures that affect pollutant dispersion (Kitada and Regmi 2003; Darby et al. 2006; Fast et al. 2006), while terrain-induced flows, such as foehn winds, are able to modify the daily cycle of pollutant concentrations in valleys (Seibert et al. 2000b). In wintertime, the snow cover plays an important role, since the mixing of pollutants is less effective in snow-covered valleys than in valleys free of snow (Chazette et al. 2005).

Dispersion is not only affected by valley winds but also by slope winds. After sunrise thermally-induced upslope winds carry pollutants that have accumulated during the night at the valley floor, upward along the slope (Bader and Whiteman 1989; Whiteman 1989). Pollutants remain either trapped in a closed slope-flow circulation (Reuten et al. 2005) or are vented out of the valley into the free atmosphere (Kossmann et al. 1999; De Wekker et al. 2004); factors favouring trapping or venting are discussed in Reuten et al. (2007). An elevated inversion layer favours trapping due to a reduction of the mass flux in the slope wind layer (Vergeiner and Dreiseitl 1987). Asymmetric thermal forcing, i.e. a difference in insolation between the two slopes, favours the development of a one-sided circulation that can be modified by the prevailing flow above the valley (Hennemuth 1986), while an asymmetric secondary circulation may also develop as a result of a sharp curvature in the along-valley topography (Weigel and Rotach 2004). Both effects result in an asymmetric distribution of pollutants across the valley (Carnuth and Trickl 2000). Upslope flows and convection near slopes may form elevated pollution layers (Wakimoto and McElroy 1986; McKendry et al. 1997), and in the evening katabatic downslope winds transport pollutants back to the valley floor (Lee et al. 2003). The recirculation of pollutants by local winds has also been found in mountain basins (Triantafyllou and Kassomenos 2002) and valleys close to the coast (Martilli and Steyn 2007).

The air pollution problem in the Inn Valley $\left(47^{\circ} 20^{\prime} \mathrm{N}, 11^{\circ} 41^{\prime} \mathrm{E}\right)$, the target area of the present study, is associated, with other factors, with heavy goods traffic (Wotawa et al. 2000; Beauchamp et al. 2004; Schnitzhofer et al. 2008). The Brenner route, i.e. the A12/A13 motorway running through the Inn Valley and Wipp Valley over the Brenner pass (Fig. 1a), is one of the major routes for the transport of goods across the Alps. For the central Alps, including the Brenner, the volume of trans-Alpine freight transport has almost doubled between 1980 and 1999 (Molitor et al. 2001). For the A12 motorway in the lower Inn Valley a further increase in total vehicle counts of 9 percent has been observed for the period 1999 to 2007. ${ }^{1}$ The pollution problem is especially severe in the cold season (Wotawa et al. 2000), and a recent

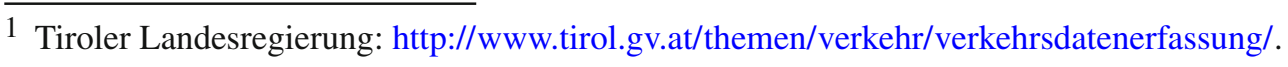



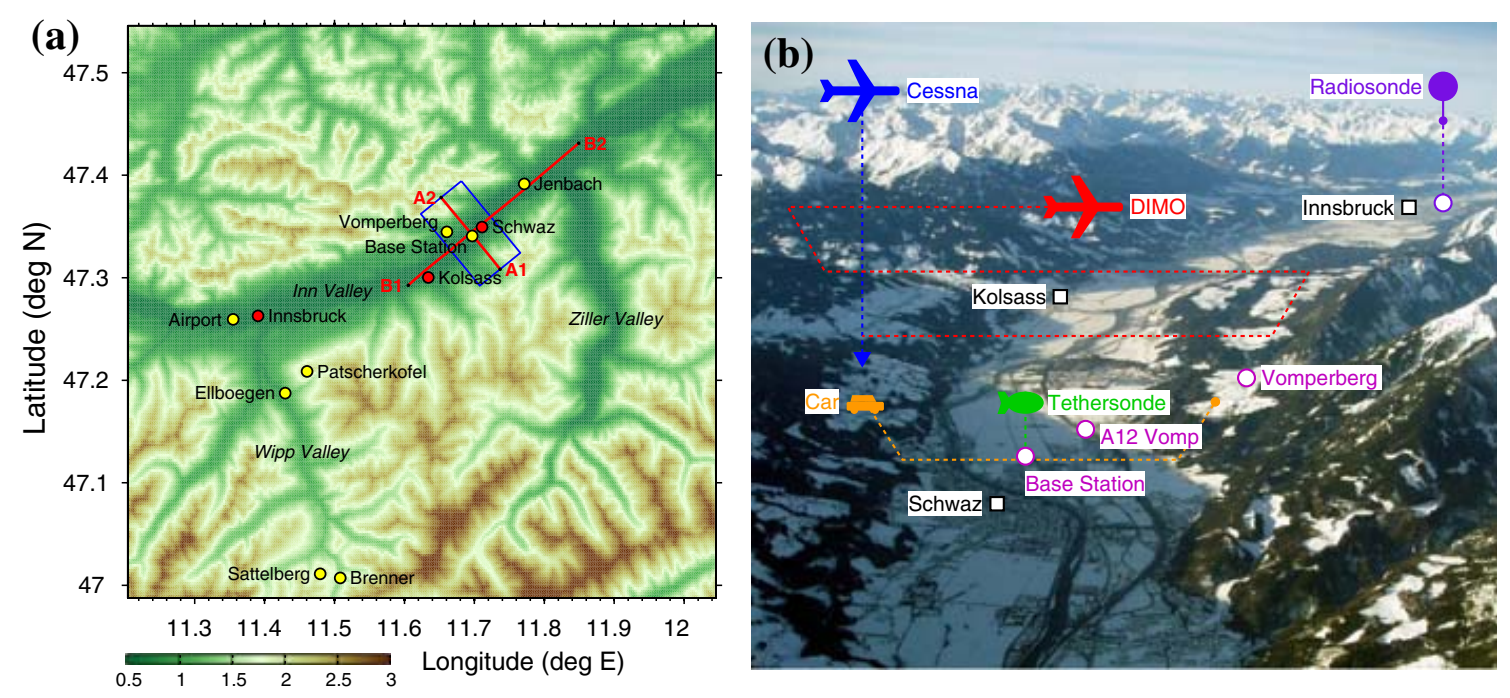

Fig. 1 The target area: a Elevation contours (km m.s.l.) of the topography. Yellow and red markers indicate the locations of measurement sites and towns, respectively, that are relevant to the present study. Red lines are two flight legs of the DLR Cessna, one across (A1A2) and one along (B1B2) the Inn Valley. A blue box illustrates the area covered by the flight path of the MetAir DIMO. Major valleys are labelled with italic letters. b Aerial photography taken at 0919 UTC 01 February 2006 looking south-westward and schematic illustration of the instrumental set-up. Dashed lines indicate measured sections of mobile instruments

wintertime field campaign attempted to elucidate meteorological processes that govern the dispersion of air pollution and noise in the lower Inn Valley (see Chap. 7.1 in Heimann et al. 2007). First results are documented in Emeis et al. (2007), Schäfer et al. (2008), and Harnisch et al. (2009). The present paper follows up on these efforts and draws a more comprehensive picture of different types of air pollution transport by analysing four selected pollution events. We try to answer the following scientific questions: How are pollutants distributed in the three-dimensional volume of the valley atmosphere? What role do local winds play in causing this distribution? The remainder of the paper is structured as follows: Sect. 2 introduces the dataset. Results are presented in Sect. 3, and Sect. 4 discusses and summarises three types of transport mechanisms inferred from the observations. The conclusions are given in Sect. 5 .

\section{Dataset}

\subsection{Field Campaign}

The dataset analysed in this study was collected in the lower Inn Valley between November 2005 and February 2006 during the field campaign of the ALPNAP ${ }^{2}$ project (Heimann et al. 2007). ALPNAP focused on ground-based observations (see Sect.2.3). Two interrelated EUFAR $^{3}$ projects (INNAP: Boundary Layer Structure in the Inn Valley during High Air Pollution; INNOX: $\mathrm{NO}_{x}$ Structure in the Inn Valley during High Air Pollution) enabled additional airborne measurements on selected days in January and February 2006 (see Sect. 2.2). Figure 1 shows the target area and the experimental set-up relevant to this study.

\footnotetext{
2 ALPNAP: Monitoring and Minimisation of Traffic-Induced Noise and Air Pollution Along Major Alpine Transport Routes - an EU funded project in the INTERREG IIIB Alpine Space Programme.

3 EUFAR: European Fleet for Airborne Research-an Infrastructure Cooperation Network of the European Commission HPRI programme under FP5/FP6.
} 


\subsection{Airborne Observations}

The key measurements were performed on two research aircraft. The DLR ${ }^{4}$ Cessna Grand Caravan conducted measurements along straight legs at a constant altitude of $\approx 3.6 \mathrm{~km}$ above mean sea level (m.s.l.); two of these legs, A1A2 and B1B2, are shown in Fig. 1a. The aircraft carried the DLR TropOLEX lidar (Meister et al. 2003), which was used as a downward looking aerosol backscatter lidar in order to observe vertical profiles of aerosol backscatter intensity. Several consecutive profiles along a specific leg form a vertical data "curtain". In this study we use data from the 1,064-nm wavelength channel with a spatial resolution of $\approx 40 \mathrm{~m}$ in the horizontal and $15 \mathrm{~m}$ in the vertical direction, respectively. The backscatter intensity is proportional to the number and size of aerosols in each resolved volume, and is therefore a qualitative measure for the amount of particulate matter and can be compared to profiles of particle number or mass concentration (density) such as PM10 (particulate matter with a diameter of $10 \mu \mathrm{m}$ or less). The small research aircraft MetAir DIMO performed in situ measurements of several air chemical and meteorological parameters. In this study we show observations of aerosol number concentration for particles with diameters greater than $0.3 \mu \mathrm{m}\left(\mathrm{N}_{d 03}\right)$, volume mixing ratio of $\mathrm{NO}_{2}$, potential temperature and wind. Harnisch et al. (2009) describe the procedure for deriving $N_{d 03}$ based on data from two instruments. The DIMO mapped the valley atmosphere along several vertically staggered legs (Fig. 1b) close to the transect A1A2 (inside of the blue box in Fig. 1a). The vertical spacing of the legs is between 150 and $300 \mathrm{~m}$. Due to the narrow valley, legs close to the ground had to be flown as loops instead of straight lines. We focus our analysis on those 4 days for which we have lidar data, and DIMO data are available for three of these 4 days. More details on aircraft data processing and first results can be found in Harnisch (2007) and Harnisch et al. (2009). Instrumented balloons, operated from the ground, are discussed in the next section.

\subsection{Ground-based Observations}

An overview of all ground-based instruments deployed during the ALPNAP field campaign can be found in Sect.7.1 of Heimann et al. (2007). For this study we only use data from a subset of instruments (see Fig. 1b). From the so-called base station, located at the valley floor near the town Schwaz at $540 \mathrm{~m}$ m.s.l., we show observations from an automatic weather station (AWS), a 10-m tower, the IMK-IFU ${ }^{5}$ mobile air quality station $\left(\mathrm{NO}_{x}\right.$ and PM10) and a tethered balloon (wind and PM10). A second AWS, located at one of the valley slopes at Vomperberg $(830 \mathrm{~mm} . \mathrm{s} .1$.), is used together with the base station for an analysis of the average daily pattern of static stability. Data from a traffic count station near Vomp illustrate the average traffic flow on the A12 motorway (see Fig. 1b), where the distance between the motorway and the base station is about $800 \mathrm{~m}$. An instrumented car provides vertical slope profiles of PM10 for each valley side. For three cases, vertical profiles of potential temperature and wind are constructed from DIMO aircraft observations. A radiosonde ascent at the airport of Innsbruck provides a vertical profile for the fourth case for which no DIMO data are available. A comparison between radiosonde and DIMO observations (not shown) reveals very good agreement in the potential temperature profile, except for an about 100-m deep layer close to the surface, whereas the radiosonde wind profile below crest level is often influenced by outflow from the Wipp Valley and therefore less representative for the target area (see Fig. 1a).

4 DLR: Deutsches Zentrum für Luft- und Raumfahrt.

5 IMK-IFU: Institute for Meteorology and Climate Research-Atmospheric Environmental Research. 

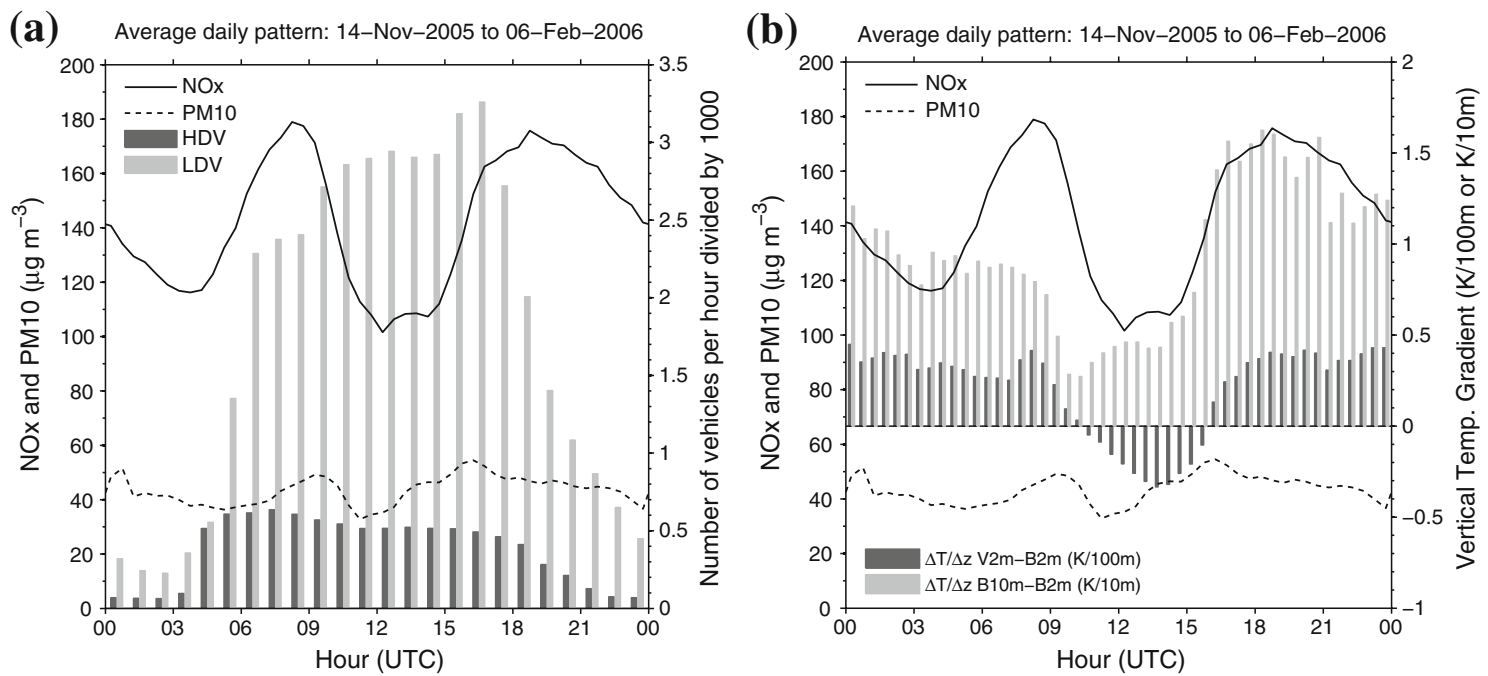

Fig. 2 Average daily pattern of air pollution, traffic, and meteorological parameters derived for the period of 14 November 2005 to 06 February 2006: $\mathbf{a ~} \mathrm{NO}_{x}\left(\mu \mathrm{g} \mathrm{m}^{-3}\right)$ as solid line and PM10 $\left(\mu \mathrm{g} \mathrm{m}^{-3}\right)$ as dashed line measured at the base station (540 m m.s.1.). Traffic flow on the A12 motorway near Vomp: number of heavy duty vehicles (HDV) and light duty vehicles (LDV) per hour (divided by 1,000) as dark grey and light grey bars, respectively. b $\mathrm{NO}_{x}$ and PM10 as in (a) together with the vertical gradient of air temperature derived from the 2-ma.g.l. temperature difference between station Vomperberg $(830 \mathrm{~mm} . \mathrm{s} .1$. $)$ and the base station (dark grey bar; $\mathrm{K}(100 \mathrm{~m})^{-1}$ ) and from the difference between 10 and $2 \mathrm{~m}$ a.g.l. at the base station (light grey bar; $\left.\mathrm{K}(10 \mathrm{~m})^{-1}\right)$. The temporal resolution is $1 \mathrm{~h}$ for traffic data and $0.5 \mathrm{~h}$ for other parameters

\section{Results}

\subsection{Mean Diurnal Pattern of Air Pollution}

Near-surface concentrations of air pollutants are governed by the rates of emission, chemical transformation and deposition as well as the rates of transport and mixing. The effect of emission and turbulent mixing on the time series of $\mathrm{NO}_{x}$ and PM10 is demonstrated in Fig. 2, where we show the average daily pattern of these two pollutants observed at the base station and derived for the period 14 November 2005 to 6 February 2006. This can be compared in Fig. $2 \mathrm{a}$ to the average traffic flow of heavy duty vehicles $\left(\mathrm{HDV}^{6}\right)$ and light duty vehicles $\left(\mathrm{LDV}^{7}\right)$ on the A12 motorway near Vomp (see Fig. 1b), which is a qualitative measure of the contribution of traffic to the total emission, and in Fig. $2 b$ to the average static stability of the atmosphere described by the vertical temperature gradients of two atmospheric layers. Concentrations are characterised by two peaks, one in the morning and one in the evening, and by a minimum around noon. The two maxima correspond to high traffic flow and high thermal stability of the boundary layer, i.e. high emission rates and weak turbulent mixing, respectively. During daytime the effect of turbulent mixing outweighs the effect of emission and causes a minimum in concentrations. Daytime heating produces a reduction of the static stability and therefore enhances turbulent mixing. The stability in the lowest few metres above the ground has a stronger impact on the surface concentrations of pollutants than the stability in a 300-m deep layer, a result that becomes obvious from a comparison of the two stability parameters in Fig. $2 \mathrm{~b}$ with the time series of $\mathrm{NO}_{x}$ and PM10. The diurnal cycle is stronger for $\mathrm{NO}_{x}$, which has a stronger dependency on traffic flow and a shorter lifetime than PM10. According to Wotawa et al. (2000) the contribution of road traffic to the total

\footnotetext{
6 HDV: truck, bus, passenger car with trailer.

7 LDV: motorcycle, passenger car, van.
} 
Table 1 Description and summary of the observed events: atmospheric setting and processes

\begin{tabular}{|c|c|c|c|c|c|c|}
\hline Date & $\begin{array}{l}\text { Large-/ } \\
\text { meso-scale } \\
\text { flow }\end{array}$ & $\begin{array}{l}\text { Wind@700hPa } \\
\left(\mathrm{ms}^{-1}\right) /(\text { dir })\end{array}$ & $\begin{array}{l}\text { Stability } \\
\left(\mathrm{K} \mathrm{m}^{-1}\right)\end{array}$ & $\begin{array}{l}\text { Radiation } \\
\left(\mathrm{MJ} \mathrm{m}^{-2}\right) / \\
\left(\mathrm{W} \mathrm{m}^{-2}\right)\end{array}$ & $\begin{array}{l}\text { Transport } \\
\text { process }\end{array}$ & Figure \\
\hline 16 Jan 2006 & Shallow foehn & 4/SW & 0.015 & $6.6 / 386$ & Density current & $10 \mathrm{a}$ \\
\hline 24 Jan 2006 & $\begin{array}{l}\text { Weak large-scale } \\
\text { flow }\end{array}$ & $5 / \mathrm{E}$ & 0.007 & $7.8 / 427$ & Slope winds & $10 \mathrm{c}$ \\
\hline 25 Jan 2006 & "Sandwich" foehn & 5/WSW & 0.015 & $5.0 / 278$ & $\begin{array}{l}\text { Back-and-forth } \\
\text { valley winds }\end{array}$ & $10 b$ \\
\hline 01 Feb 2006 & High pressure & 2/SW & 0.016 & $7.2 / 423$ & Slope winds & $10 \mathrm{c}$ \\
\hline
\end{tabular}

Column 2: Large-scale or mesoscale flow. Column 3: wind speed $\left(\mathrm{m} \mathrm{s}^{-1}\right)$ and direction at $700 \mathrm{hPa}$ of the ECMWF analysis at $1200 \mathrm{UTC}$ for grid point $47^{\circ} \mathrm{N}, 12^{\circ} \mathrm{E}$. Column 4 : average vertical stability $\partial \theta / \partial z$ in the lowest few hundred metres above the ground taken from Fig. 3a. Column 5: global radiation at the base station integrated over $24 \mathrm{~h}\left(\mathrm{MJ} \mathrm{m}^{-2}\right)$ and the daily maximum $\left(\mathrm{W} \mathrm{m}^{-2}\right)$ based on 30-min averages taken from Fig. 4. Column 6 and 7: prominent transport process and reference to figure

$\mathrm{NO}_{x}$ emission is $85 \%$ in the lower Inn Valley, from which $55 \%$ can be attributed to the $\mathrm{A} 12$ motorway. In the same region in winter the two biggest emission sources of PM10 are road traffic with 35\% and domestic burning with 25\% (Umweltbundesamt 2004).

The described diurnal pattern has also been observed for individual wintertime days and for other seasons (e.g., Wotawa et al. 2000; Heimann et al. 2007; Schäfer et al. 2008). The modification of this pattern on days with HDV bans has also been documented by e.g., Beauchamp et al. (2004) and Schnitzhofer et al. (2008). Nevertheless, strong differences in concentrations occur from day to day. For the data in Fig. 2a these variations are reflected in high values of standard deviations, which are on average (i.e., for the whole 24-h period) $\approx 100 \mu \mathrm{g} \mathrm{m}^{-3}$ for $\mathrm{NO}_{x}$ and $\approx 30 \mu \mathrm{g} \mathrm{m}^{-3}$ for PM10. Normalised by the arithmetic mean, these values correspond to $69 \%$ and $64 \%$, respectively, while the corresponding relative standard deviation for traffic flow is weaker, with $24 \%$ for LDV and $45 \%$ for HDV. One of the main purposes of this paper is to show that the average daily pattern is superposed by fluctuations and atypical behaviour that cannot be explained by local factors alone, such as changes in stability and emission, but require a three-dimensional view of the problem in order to understand the underlying transport processes. We now focus on four specific cases in order to corroborate this statement; Table 1 provides an overview of the atmospheric setting and the relevant processes.

\subsection{Transport by a Density Current}

The first case on 16 January 2006 illustrates the impact of differences in air-mass properties along the valley on the temporal evolution of the concentrations of air pollutants at the base station. We will show that advection of pollutants by a density-current-like flow was responsible for a rapid increase in concentrations.

\subsubsection{Mesoscale Background}

A weak cut-off low passed the Alps between 15 and 17 January 2006, moving from Italy over Austria to the Czech Republic. In our target area, the lower Inn Valley, this low pressure system produced neither precipitation nor clouds on 16 January, though the system was responsible for low-level temperature and pressure differences between the southern and northern Alpine forelands. The Italian Po Valley south of the Alps was filled with cooler 

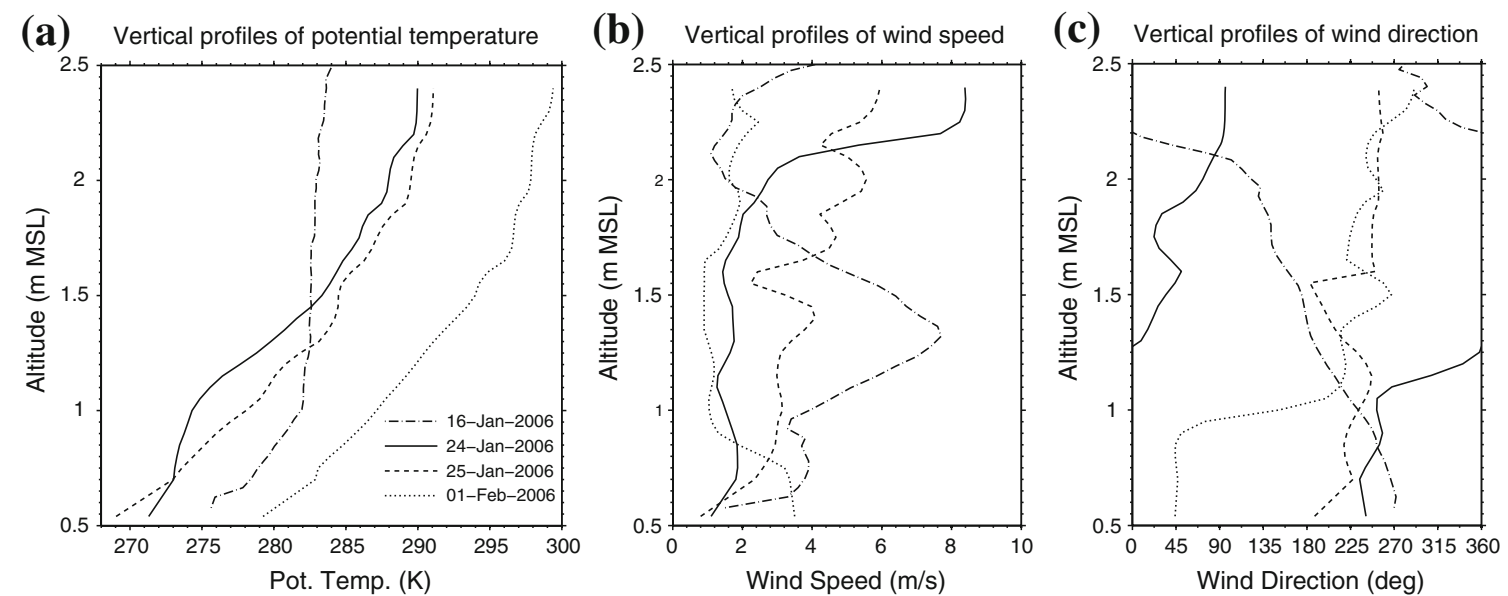

Fig. 3 Vertical profiles of (a) potential temperature $(\mathrm{K}),(\mathbf{b})$ wind speed $\left(\mathrm{ms}^{-1}\right)$, and (c) wind direction (degrees) in the Inn Valley at about 1500 UTC 16 January (dashed-dotted), 1400 UTC 24 January (solid), 1200 UTC 25 January (dashed), and 1500 UTC 01 February 2006 (dotted). For the profile on 16 January, data are taken from a radiosonde ascent at Innsbruck Airport. The other profiles are compiled from MetAir DIMO observations combined with near-surface measurements at the base station

air compared to the Bavarian Alpine foreland north of the Alps. This mesoscale air-mass difference induced a southerly flow through mountain gaps such as the Brenner Pass. This type of compensation flow is known as a shallow south foehn (e.g., Gohm et al. 2004) and is restricted to heights below the Alpine crest level. It can be identified as a southerly downvalley flow in the Wipp Valley with speeds of about $8 \mathrm{~m} \mathrm{~s}^{-1}$ at 1400 UTC observed at the AWS Ellboegen and Patscherkofel (see Fig. 1a; data not shown) and as a southerly low-level jet in the Innsbruck radiosonde ascent at 1500 UTC (Fig. 3). The sounding also shows that the foehn at the exit of the Wipp Valley did not reach the floor of the Inn Valley but was trapped in a nearly mixed (neutral) layer between $\approx 1$ to $2 \mathrm{~km} \mathrm{~m}$.s.l. A 500-m deep very stable layer above the surface $\left(\partial \theta / \partial z \approx 0.015 \mathrm{~K} \mathrm{~m}^{-1}\right)$, with westerly winds down the Inn Valley, inhibited the breakthrough of the foehn at Innsbruck. For the target area located $\approx 30 \mathrm{~km}$ east of Innsbruck and for the period before 1500 UTC, this westerly downvalley flow is supported by measurements of near-surface winds at the base station (Fig. 4a) and by tethered balloon soundings ( $u_{\mathrm{val}}>0$ in Fig. 5a). The parameter $u_{\mathrm{val}}$ is the wind component along the valley pointing in a north-eastward direction (positive for downvalley flow). Although we do not have wind profiles to high enough levels to capture the whole valley atmosphere, we believe that the flow in the target area was mainly channelled by the Inn Valley. Gohm et al. (2004) showed that the shallow foehn jet from the Wipp Valley is mainly deflected into the lower Inn Valley, which leads in our case and target area to enhanced downvalley flow above the stable surface layer. Important for the following discussion is the fact that the air in the lower Inn Valley close to the surface was cooler than at Innsbruck. At 1500 UTC the air temperature at Jenbach was $2 \mathrm{~K}$ below that of Innsbruck and the reduced pressure was about $0.7 \mathrm{hPa}$ higher (see Fig. 1a; data not shown). The low-level downvalley flow did not reach Jenbach, as suggested by upvalley winds at the base station at about 1500 UTC in Fig. 4a.

\subsubsection{Diurnal Pattern at the Surface}

Fair-weather conditions on 16 January are illustrated in Fig. 4a by an undisturbed cycle of global radiation and temperature at the base station. The diurnal evolution of the concentrations of $\mathrm{NO}_{x}$ and PM10 is very similar to the mean pattern discussed in Sect.3.1. Peaks of $\mathrm{NO}_{x}$ concentration occur in the morning and evening with values greater than $400 \mu \mathrm{gm}^{-3}$; 

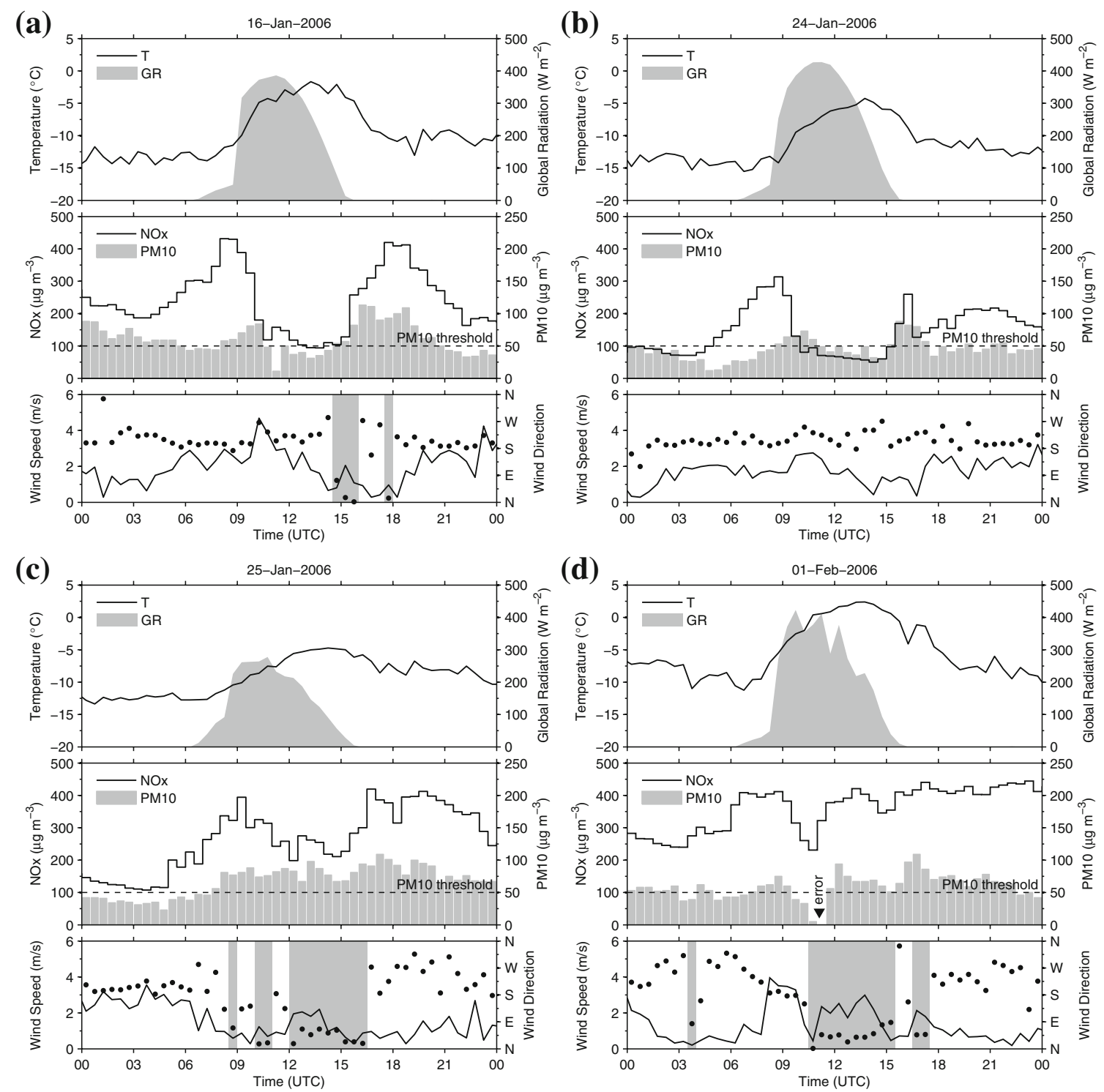

Fig. 4 Time series of near-surface observations from the base station on a 16 January, b 24 January, c 25 January, and d 01 February 2006: (top panel) air temperature $\left({ }^{\circ} \mathrm{C}\right)$ as solid line and global radiation $\left(\mathrm{W} \mathrm{m}^{-2}\right)$ as shaded area, (middle panel) $\mathrm{NO}_{x}\left(\mu \mathrm{g} \mathrm{m}^{-3}\right)$ as solid line and PM10 $\left(\mu \mathrm{g} \mathrm{m}^{-3}\right)$ as bars, and (bottom panel) wind speed $\left(\mathrm{m} \mathrm{s}^{-1}\right)$ as solid line and wind direction as dots. Grey shaded regions in the bottom panel indicate periods of upvalley winds. The temporal resolution is $30 \mathrm{~min}$

the 24-h average of PM10 exceeds the threshold of $50 \mu \mathrm{gm}^{-3}$ prescribed by the EU Council Directive 1999/30/EC. Daytime heating of the boundary layer causes a significant reduction in concentrations (about $75 \%$ for $\mathrm{NO}_{x}$ ), and we presume that the rapid increase after 1500 UTC is not merely caused by radiative cooling and a corresponding increase in static stability, but is significantly enhanced by advection in conjunction with a flow reversal, i.e. a shift to upvalley winds. This feature is described in the following sections in more detail.

\subsubsection{Spatial Distribution of Pollutants}

Figure 6a shows the vertical structure of PM10 as measured by the tethered balloon in the middle of the valley and by the instrumented car along the two valley slopes. Shown are profiles before 1500 UTC that are not yet influenced by the mentioned wind reversal. The striking feature is an $80-100-\mathrm{m}$ deep polluted layer near the surface that is topped by 

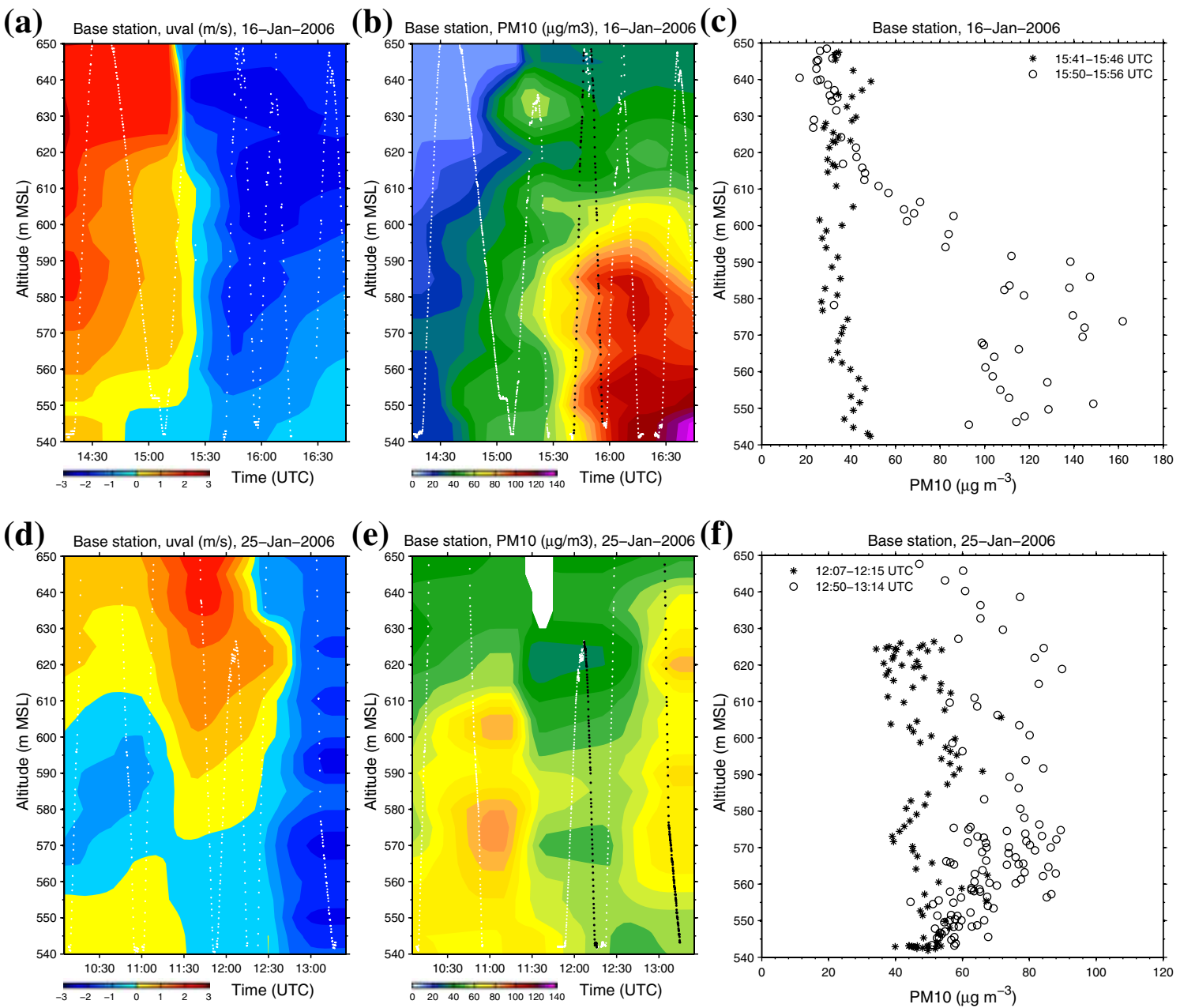

Fig. 5 Tethered balloon soundings at the base station on (a-c) 16 January 2006 and (d-f) 25 January 2006: Hovmöller-type diagrams (altitude versus time) of (a) and (d) along-valley wind component $u_{\mathrm{val}}\left(\mathrm{ms}^{-1}\right.$ ) and (b) and (e) PM10 $\left(\mu \mathrm{g} \mathrm{m}^{-3}\right)$ for the period (a-b) 1415 to 1645 UTC and (d-e) 1005 to 1325 UTC. Increments of colour contours are $0.5 \mathrm{~m} \mathrm{~s}^{-1}$ and $20 \mu \mathrm{g} \mathrm{m}^{-3}$, respectively. Positive (negative) values of $u_{\mathrm{val}}$ indicate downvalley (upvalley) flow. Vertical profiles of PM10 $\left(\mathrm{\mu g} \mathrm{m}^{-3}\right)$ at about (c) 1543 UTC (stars) and 1553 UTC (circles) and (f) 1211 UTC (stars) and 1302 UTC (circles). White dots in (a-b) and (d-e) indicate locations of individual measurements. Black dots in (b) and (e) indicate data points shown in (c) and (f), respectively

relatively clean air $\left(\mathrm{PM} 10 \approx 10 \mu \mathrm{g} \mathrm{m}^{-3}\right)$; this layer corresponds to a mixing-layer height of $\approx 100 \mathrm{~m}$ derived from sodar measurements (Schäfer et al. 2008; their Fig. 7). Typical PM10 values in the polluted layer of $\approx 40 \mu \mathrm{g} \mathrm{m}^{-3}$ agree with near-surface values in Fig. 4 a before the time of the wind reversal. The three profiles in Fig. 6a show similar concentrations in the lowest few decametres above the valley floor. However, higher above, the north-west facing (shaded) valley slope appears to be less polluted than the south-east facing (sun-exposed) slope and the air column at the middle of the valley (see Fig. 1 for slope orientation).

The shallow polluted layer is also captured by the lidar observations. In the transect A1A2 (Fig. 7a), aligned across the valley, this layer is about $130 \mathrm{~m}$ deep and marked by very high backscatter intensities (reddish colours). At the shown time the layer depth is homogeneous in the cross-valley direction. However, in a transect conducted about $25 \mathrm{~min}$ earlier (not shown), and in better agreement to Fig. $6 \mathrm{a}$, this layer is only $\approx 100 \mathrm{~m}$ deep and asymmetric, i.e. shallower on the north-west facing slope. The temperature inversion below $\approx 150 \mathrm{~m}$ above ground level (a.g.l.) (Fig. 3) results in a very thin polluted near-surface layer and prevents strong mixing. Above this near-surface inversion, but still within the 500-m deep stable layer, backscatter intensities are more than a factor of two lower. Further above, the neutrally 
(a)

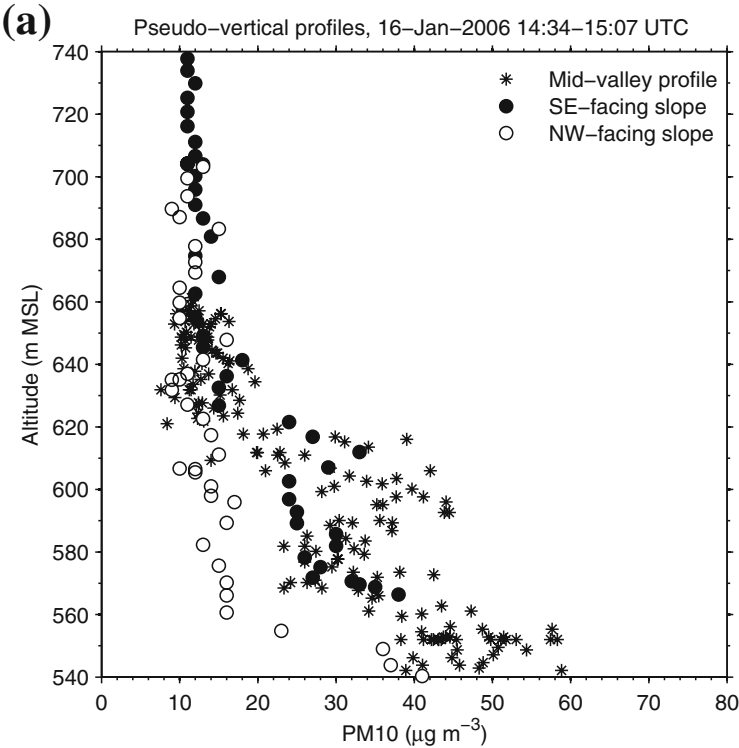

(c) Pseudo-vertical profiles, 25-Jan-2006 11:43-12:46 UTC

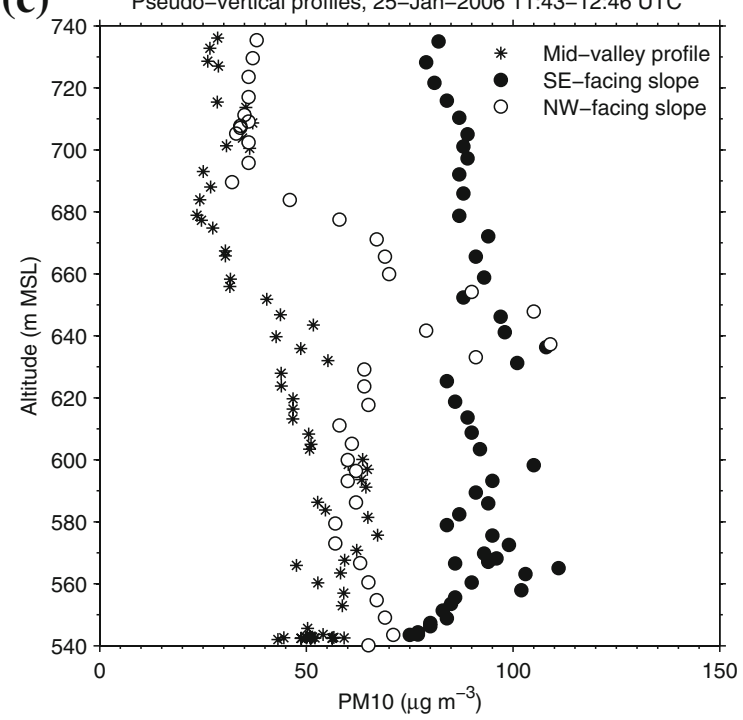

(b)

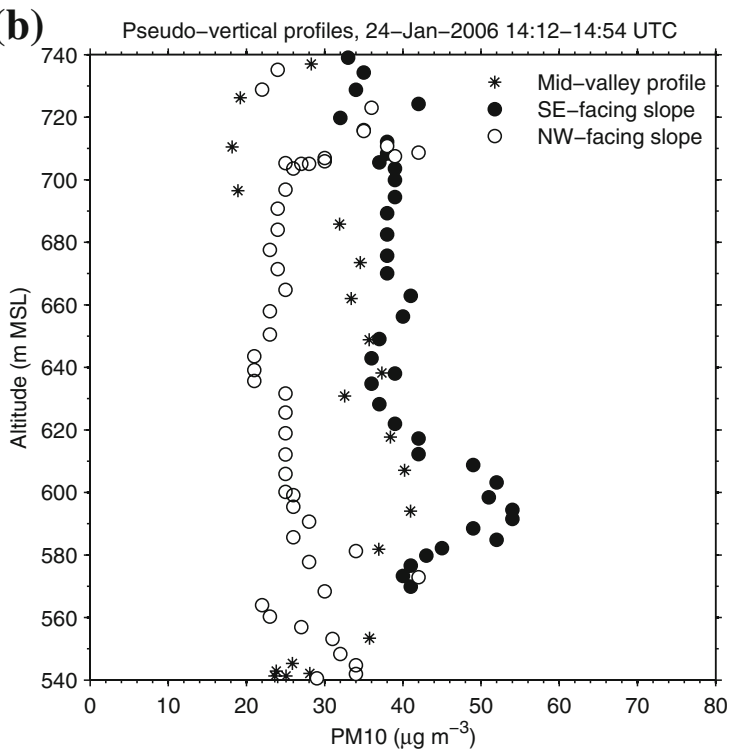

(d)

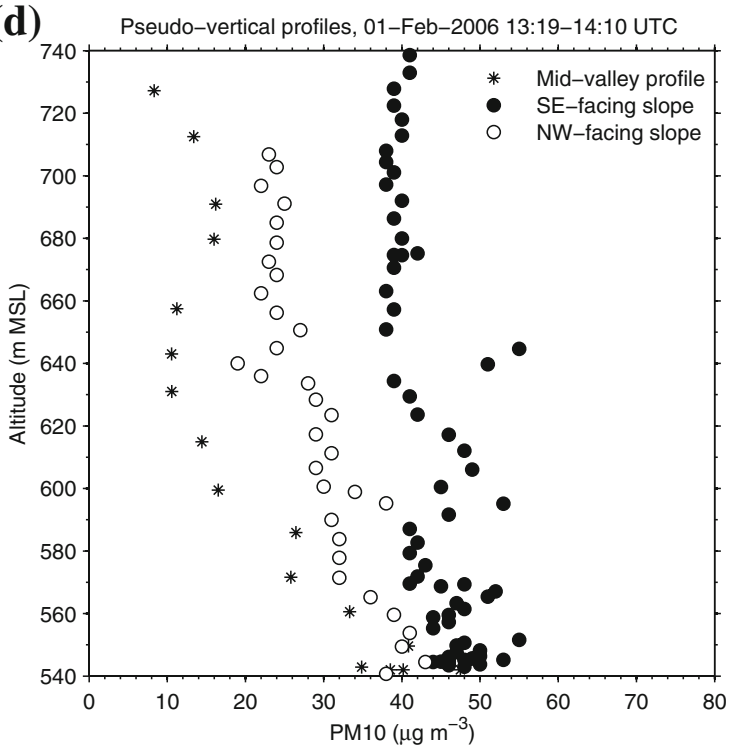

Fig. 6 Pseudo-vertical profiles of PM10 $\left(\mu \mathrm{g} \mathrm{m}^{-3}\right)$ near the base station at Schwaz along the south-east facing valley slope (filled circles), along the north-west facing valley slope (open circles) and along a true vertical profile at the valley centre (stars): about (a) 1450 UTC 16 January, (b) 1430 UTC 24 January, (c) 1215 UTC 25 January, and (d) 1345 UTC 01 February 2006. Slope data are from an instrumented car and true vertical profiles from a tethered balloon

stratified "foehn" layer with southerly winds at Innsbruck (Fig. 3) and presumably westerly winds at the base station is characterised by low aerosol concentrations. Backscatter intensities are a factor of about ten lower in the foehn layer than near the surface. In fact, the foehn layer is decoupled from the polluted near-surface layer by the 500-m deep stable layer. Mechanical turbulence (weak stability and wind shear; see Fig. 3) is presumably the reason for the well-mixed aerosol distribution in the foehn layer. Slightly higher backscatter intensities on the south-east exposed slope may be attributed to the upward transport by thermally or dynamically (foehn) driven slope winds. A combination of both effects is conceivable. This upslope transport, however, is much weaker than in the cases presented in the following sections.

The transect B1B2 in Fig. 7b shows that the aerosol structure is not homogeneous in the along-valley direction, and the top of the near-surface aerosol layer (reddish colours) is 

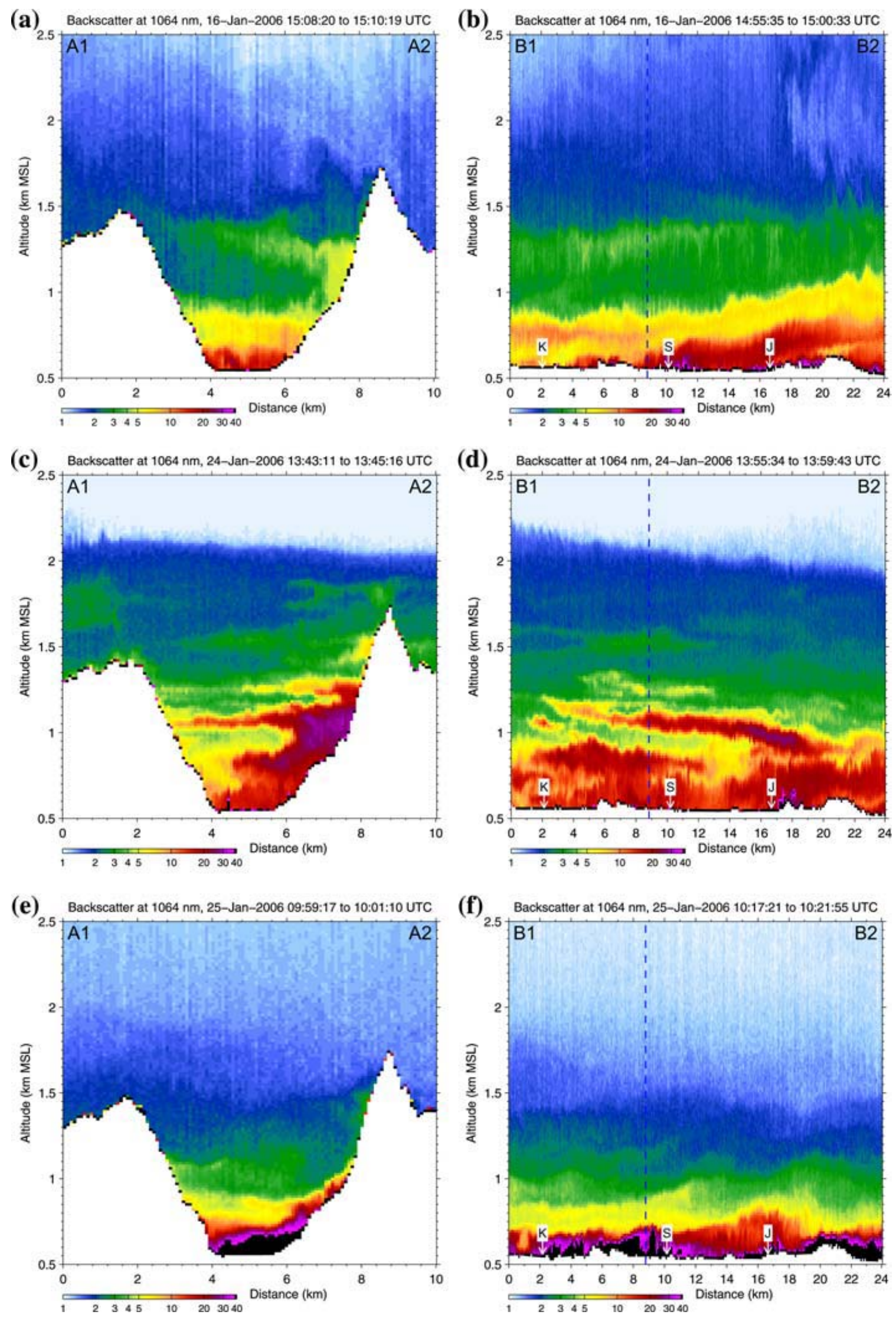

Fig. 7 Vertical transects of aerosol backscatter intensity (arbitrary units) at about (a-b) 1500 UTC 16 January 2006, (c-d) 1400 UTC 24 January 2006, (e-f) 1000 UTC 25 January 2006, and (g-h) 1400 UTC 01 February 2006: (a, c, e, g) transect across the Inn Valley (A1A2; see Fig. 1a) and (b, d, f, h) along the Inn Valley (B1B2). Labels in B1B2 show the locations of the towns Kolsass (K), Schwaz (S), and Jenbach (J) (see also Fig. 1a). A blue dashed line in $\mathrm{B} 1 \mathrm{~B} 2$ shows the intersection with transect $\mathrm{A} 1 \mathrm{~A} 2$ and also the location of the base station. Orography is white 

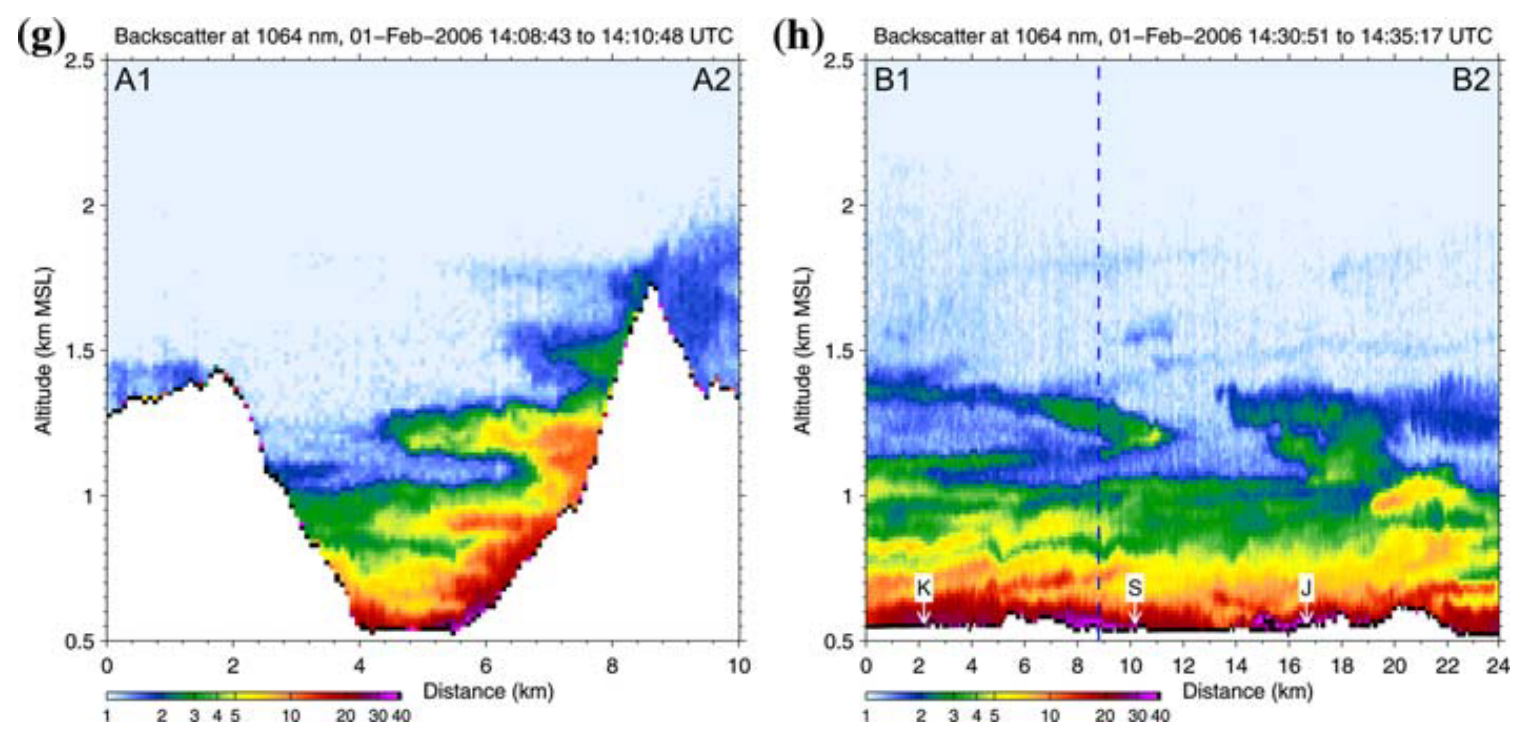

Fig. 7 continued

slanted. The polluted layer is about $200 \mathrm{~m}$ deeper and has higher aerosol concentrations in the north-eastern part of this transect (e.g., near the town of Jenbach) compared to the southwestern part (e.g., near the town of Kolsass). The north-eastern part is also characterised by local maxima of backscatter intensities close to the surface that may be ascribed to local aerosol sources at the bottom of the valley. Since the air mass was cooler in the lower Inn Valley (see Sect. 3.2.1) it is very likely that the downvalley flow observed in the western part was lifted near the town of Schwaz above the cooler and more polluted air mass residing at that time in the eastern part of the valley. In such a conceptual model streamlines or isentropes would closely follow the top of the three aerosol layers apparent in Fig. 7b.

\subsubsection{Temporal Evolution of Concentrations}

Tethered balloon soundings will now illustrate that the aerosol distribution shown in Fig. 7b was not steady. Figure 5a-b depicts the temporal evolution within the lowest 100 ma.g.l. over a period of $2.5 \mathrm{~h}$; the striking feature is a wind reversal at all levels of the profile that occurs at 1520 UTC (about 30 min earlier at the surface; see also Fig. 4a) and is accompanied by a dramatic increase of PM10 concentrations from about $40 \mu \mathrm{g} \mathrm{m}^{-3}$ to values exceeding $140 \mu \mathrm{g} \mathrm{m}^{-3}$. Two selected profiles in Fig. 5c, which are separated by only about $10 \mathrm{~min}$, illustrate this rapid increase in PM10 even better. Not only PM10 but also $\mathrm{NO}_{x}$ (see Fig. 4a) and other pollutants showed a similar increase in concentrations. The reason for this change is the upvalley movement of the shallow, cool and polluted air mass shown in Fig. 7b. Indeed, in a transect conducted about 20 min earlier (not shown), the "front" of the polluted air mass was located $\approx 1.5 \mathrm{~km}$ further downvalley. The phenomenon can be interpreted as a density current that propagates upvalley, and whose propagation causes a flow reversal at the base station and the advection of more polluted air from the lower Inn Valley.

\subsection{Transport by Slope Winds (Case 1)}

The case on 24 January 2006 illustrates the role of slope winds for the transport and dispersion of pollutants. We now show that a one-sided thermal circulation caused an asymmetric distribution of pollutants across the valley. 


\subsubsection{Mesoscale Background}

The 24 January 2006 was characterised by north-easterly winds that prevailed over the Alpine region on the rear side of a pressure trough. During previous days this system had advected cold Arctic air to central Europe. The ECMWF ${ }^{8}$ analysis (not shown) indicates that the cold-air outbreak had reached the Mediterranean at about 1200 UTC 24 January, and in the Inn Valley the advection of cold air by upvalley winds ceased in the evening of 23 January. The vertical sounding of the MetAir DIMO at about 1400 UTC 24 January in Fig. 3 shows that the atmosphere in the target area is characterised by a moderately stable layer below $1000 \mathrm{~mm}$.s.l. $\left(\partial \theta / \partial z \approx 0.007 \mathrm{~K} \mathrm{~m}^{-1}\right)$, which is topped by a $\approx 500$-m deep temperature inversion layer $\left(\partial \theta / \partial z \approx 0.018 \mathrm{~K} \mathrm{~m}^{-1}\right)$. Below $2 \mathrm{kmm}$.s.l. winds are weak and generally less than $2 \mathrm{~m} \mathrm{~s}^{-1}$ and are downvalley within the lower layer and upvalley within the inversion layer. Above crest level ( $\geq 2.2 \mathrm{~km}$ m.s.l.) north-easterly synoptic-scale winds of up to $8 \mathrm{~m} \mathrm{~s}^{-1}$ are found in the sounding.

\subsubsection{Diurnal Pattern at the Surface}

The advection of cold, aerosol rich air from the Alpine foreland contributed to rising PM10 levels. At the base station the 24-h averages of PM10 increased from 19 to $45 \mu \mathrm{g} \mathrm{m}^{-3}$ between 22 and 24 January 2006. Figure 4b illustrates the situation on 24 January. A pronounced daily cycle of air pollution concentrations is visible with a minimum around noon that is related to clear skies (see global radiation) and therefore undisturbed daytime heating of the boundary layer. Near-surface winds were downvalley throughout the day. The lack of a period of thermally driven upvalley winds in the afternoon, which was observed on other sunny days in winter (see e.g., Sect.3.5), is attributed, as in the previous case, to a small temperature difference between the air mass on the southern and northern Alpine forelands that caused a weak compensation flow through the Brenner gap. However, the "foehn wind jet" apparent in the Innsbruck sounding at 1400 UTC (not shown) is much weaker and shallower as on 16 January (Sect. 3.2).

\subsubsection{Spatial Distribution of Pollutants}

The slope and mid-valley profiles of PM10 in the early afternoon at around 1430 UTC are shown in Fig. 6b. Two features are outstanding: firstly, the polluted layer is much deeper than on 16 January and extends beyond the shown altitude, corresponding to a deeper sodarderived mixing-layer height of about 150-200 m (Schäfer et al. 2008; their Fig. 7). Secondly, the south-east facing slope and the mid-valley profile are characterised by about $60 \%$ higher PM10 values than the north-west facing slope. The first feature is caused by stronger vertical mixing due to weaker static stability close to the ground (Fig. 3a), and the second feature by cross-valley transport as shown below.

Figure 7c shows the lidar backscatter intensities across the valley. As already expected from Fig. 6b, the aerosol distribution is asymmetric with a much higher aerosol load above the sun-exposed slope compared to the other valley side. The asymmetry can also be identified in a transect conducted about 25 min later (not shown). We believe that thermally-induced upslope winds transported aerosols from the valley floor to altitudes of about $1.3 \mathrm{kmm}$.s.l. Surface-layer heating above the snow-free trees is stronger above the south-east facing slope than above the northwest-facing slope since the latter is affected by shading (see e.g., Fig. 1b).

8 ECMWF: European Centre for Medium-Range Weather Forecasts. 
This produces a stronger upslope transport above the south-east-exposed slope and consequently an asymmetric aerosol distribution. As the slope flow approaches the inversion layer (Fig. 3a) it starts to separate from the slope. Consequently, aerosols are transported horizontally away from the slope towards the opposite valley side. This horizontal transport forms at least two elevated aerosol layers, one at $\approx 1.1 \mathrm{kmm}$.s.l. and the second at $\approx 1.25 \mathrm{~km}$ m.s.l. The phenomenon can be viewed as a one-sided thermal circulation that is consistent with the conceptual model of Vergeiner and Dreiseitl (1987), who argued that an elevated inversion layer causes a reduction in the mass flux of the slope wind layer (defined by bulk values of layer depth and speed) and consequently a horizontal transport out of the slope wind layer.

In situ measurements of the MetAir DIMO support this asymmetric structure found in the lidar data and moreover show that, not only particulate matter but also other pollutants, such as $\mathrm{NO}_{2}$, are affected by the slope wind transport (Fig. 8a-b). The DIMO is not able to measure the upslope winds directly since the slope wind layer is presumably too shallow (a few decametres) and slope winds are too transient. However, the DIMO cross-section in Fig. 9a reveals weak downvalley winds in the lower part of the valley atmosphere $\left(u_{\text {val }}>0\right)$ and weak upvalley winds in the upper part $\left(u_{\text {val }}<0\right)$, which agrees with Fig. 3b-c. Nevertheless, Fig. 9a shows weak cross-valley winds at the heights of the two aerosol layers detected by the lidar. Detrainment of polluted air from the thin slope wind layer into the ambient valley atmosphere was presumably responsible for the formation of a relatively thick (a few hectometres) pollution layer aligned along the sun-exposed slope.

The elevated aerosol layer found at $\approx 1.1 \mathrm{~km}$ m.s.l. in Fig. $7 \mathrm{c}$ can also be identified in the along-valley transect shown in Fig. 7d. The layer ranges from the towns of Kolsass to Jenbach over a distance of about $16 \mathrm{~km}$ and decreases in altitude by about $300 \mathrm{~m}$. The difference in the altitude of the layer may be related to differences in the strength of the slope winds along the valley. Below about $1 \mathrm{~km}$ m.s.l. the aerosol distribution is nearly homogeneous with only weak gradients in the horizontal and vertical directions. Consequently, in this case the temporal evolution of particle concentrations at a specific site appears to be mainly determined by cross-valley transport and slope wind advection, whereas along-valley transport plays only a minor role.

\subsection{Back-and-Forth Transport by Valley Winds}

The case on 25 January 2006 exhibits an atypical behaviour of pollution concentrations around noon that is characterised by a transient increase of air pollution. We explain this feature as a recirculation of pollutants due to reversing valley winds.

\subsubsection{Mesoscale Background}

On 25 January 2006 a pressure trough approached the Alps from the north-west with associated westerly winds at crest level that increased during the day. A moderate southerly compensation flow was observed in the Wipp Valley at mountain stations (Patscherkofel, Sattelberg) in the late morning and afternoon but not at the surface (Ellboegen). This so-called "sandwich" foehn (Vergeiner and Mayr 2000) was restricted to a shallow layer in the Wipp Valley. However this southerly flow in the Wipp Valley contributed to the westerly flow in the Inn Valley. The MetAir sounding at about 1200 UTC shown in Fig. 3 depicts this downvalley flow in the target area. Enhanced westerly winds with speeds up to $\approx 6 \mathrm{~m} \mathrm{~s}^{-1}$ are visible especially above $1.2 \mathrm{~km}$ m.s.l., whereas low-level winds are weak at $1-3 \mathrm{~m} \mathrm{~s}^{-1}$. The Inn Valley is filled to a height of about $1.9 \mathrm{~km}$ m.s.l. with cold, strongly stable air $\left(\partial \theta / \partial z \approx 0.015 \mathrm{~K} \mathrm{~m}^{-1}\right)$ and with less stable air above. 

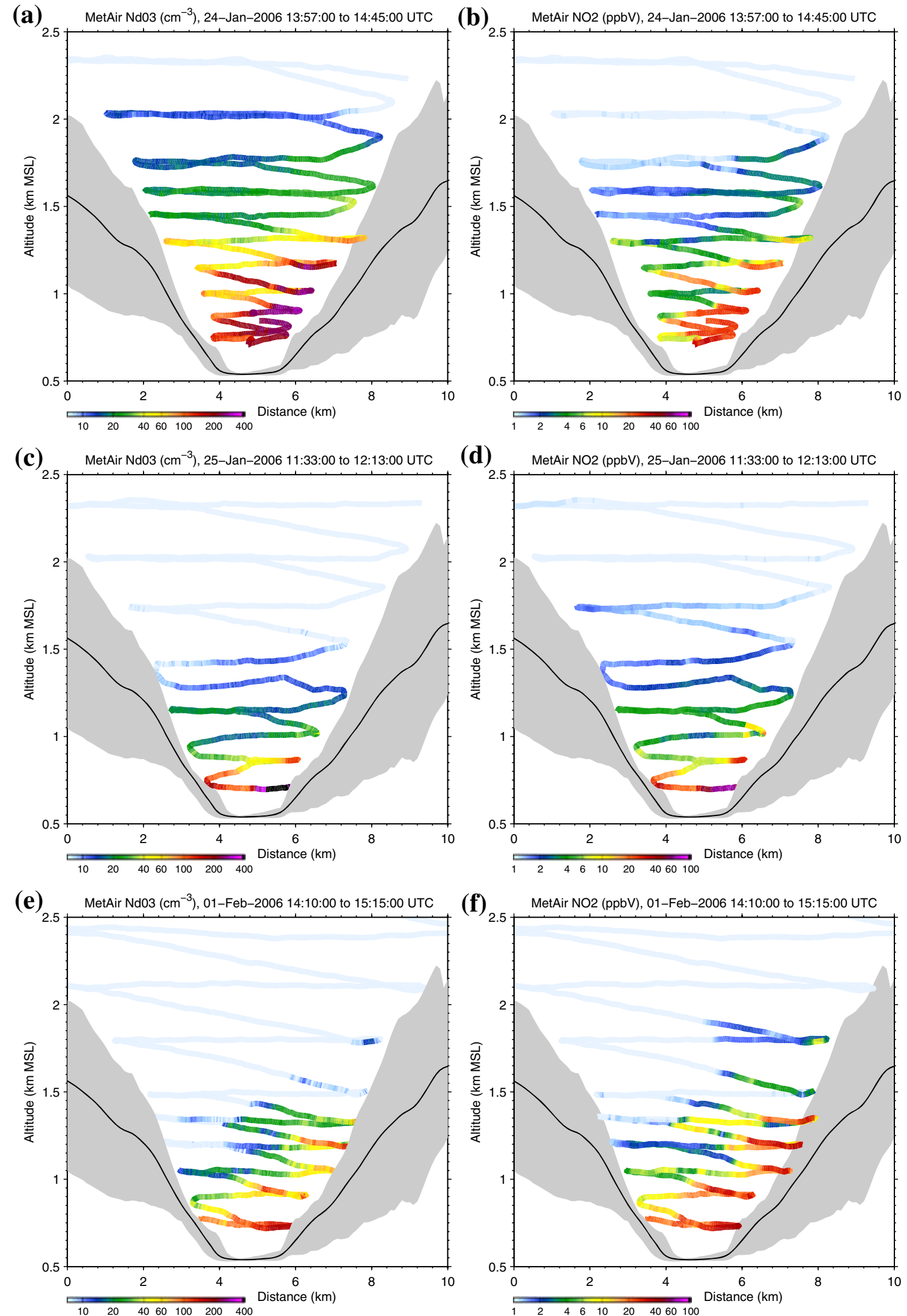

Fig. 8 MetAir DIMO in situ observations on a nearly vertical transect across the Inn Valley (see Fig. 1a) at about (a-b) 1420 UTC 24 January 2006, (c-d) 1150 UTC 25 January 2006, and (e-f) 1440 UTC 01 February 2006: (a, c, e) aerosol number concentration $N_{d 03}\left(\mathrm{~cm}^{-3}\right)$ for particles with diameters greater than $0.3 \mu \mathrm{m} ;(\mathbf{b}$, d, f) volume mixing ratio of $\mathrm{NO}_{2}(\mathrm{ppbV})$. The average height of the orography within a box that surrounds the flight path (see Fig. 1a) is drawn as the black line and the spread between the minimum and maximum topography within this box as the grey surface 

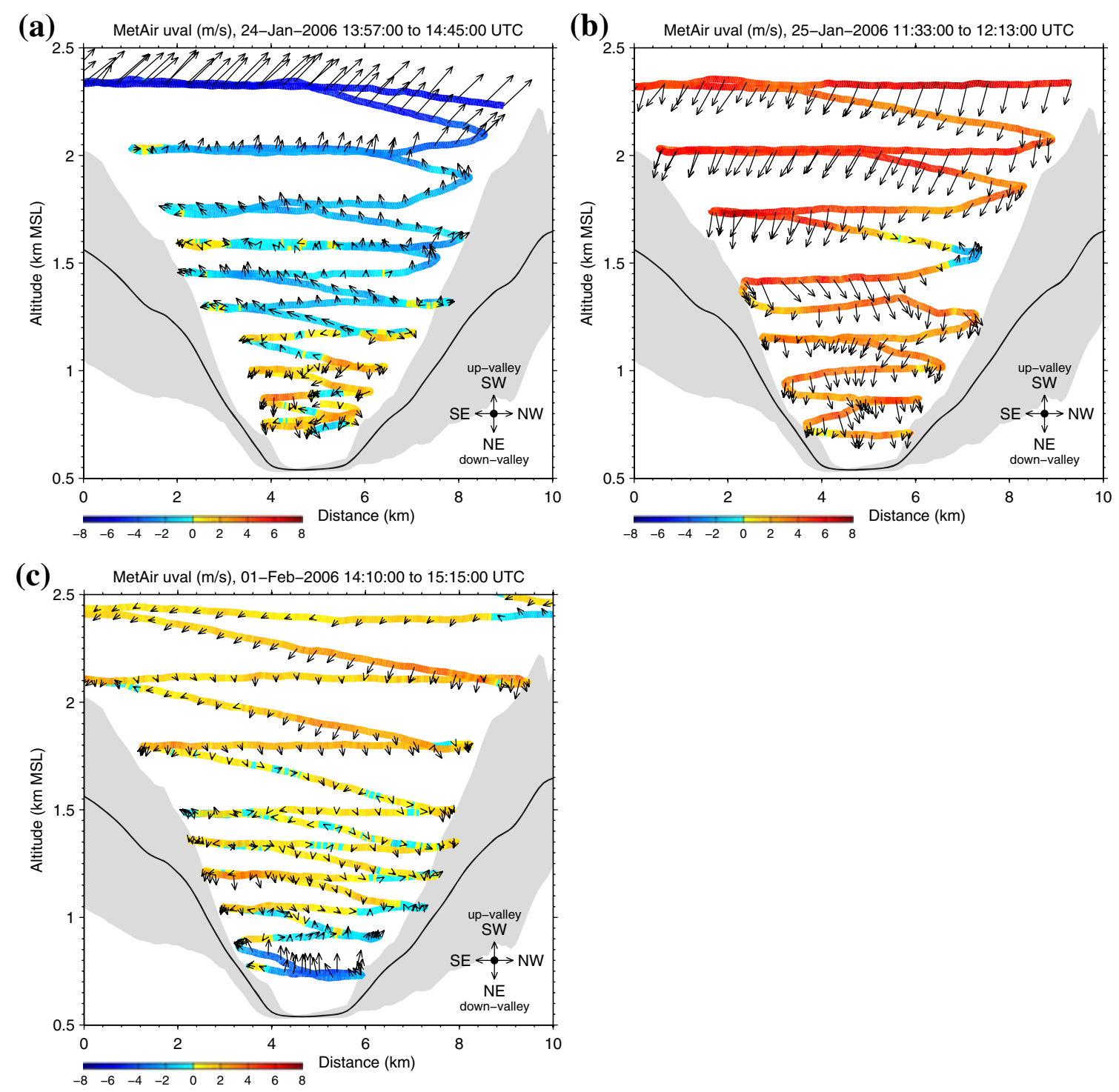

Fig. 9 As in Fig. 8 but for the along-valley wind component $u_{\mathrm{val}}\left(\mathrm{m} \mathrm{s}^{-1}\right)$ with horizontal wind vectors at about a 1420 UTC 24 January 2006, b 1150 UTC 25 January 2006, and c 1440 UTC 01 February 2006. Positive (negative) values of $u_{\mathrm{val}}$ indicate downvalley (upvalley) flow. The compass rose in the lower right corner shows the horizontal coordinate system for the wind vectors. The length of the four reference vectors in the compass rose corresponds to a horizontal wind speed of $4 \mathrm{~m} \mathrm{~s}^{-1}$

\subsubsection{Diurnal Pattern at the Surface}

High clouds associated with the approaching trough were responsible for a disturbed cycle of global radiation (Fig. 4c). Consequently, daytime heating was weaker than in the previous cases, and pollution concentrations were generally high. The daily average PM10 concentration of $67 \mu \mathrm{g} \mathrm{m}^{-3}$ violated the EU guideline limit of $50 \mu \mathrm{g} \mathrm{m}^{-3}$. The temporal evolution of $\mathrm{NO}_{x}$ and PM10 shown in Fig. 4c has similarities to the average diurnal cycle discussed in Sect. 3.1 with a maximum in the morning and early evening. However, a closer inspection reveals an atypical secondary maximum in pollution concentrations between 1200 and 1500 UTC, which is associated with a period of upvalley winds. Two shorter periods of weaker upvalley winds occurred before 1200 UTC. The effect of the main wind reversal on the pollution concentrations is now explored in more detail. 


\subsubsection{Spatial Distribution of Pollutants}

Figure $6 \mathrm{c}$ illustrates the PM10 profiles measured by the car and the tethersonde at around 1215 UTC. As in the previous case, the south-east facing slope exhibits the highest PM10 concentrations, and are about $30 \%$ higher, averaged over the lowest $100 \mathrm{~m}$ a.g.l., than in the middle of the valley and above the opposite valley slope. The latter two show a decrease in concentrations at about $100-150 \mathrm{~m}$ a.g.l. The average sodar-derived mixing-layer height is about $150 \mathrm{~m}$ on this day (Schäfer et al. 2008; their Fig. 7). As these PM10 profiles are collected over a period of about $1 \mathrm{~h}$, and as the temporal variation within this period is rather high (see Fig. 5e), the illustrated asymmetry might be less clear at a different time. Nevertheless, one anticipates strong horizontal gradients in pollution concentrations.

These gradients become apparent in the two transects of aerosol backscatter intensity at around 1000 UTC (Fig. 7e-f). Unfortunately, no lidar data are available that show the situation at noon and early afternoon. Nevertheless, in agreement with the previous PM10 profiles, the cross-valley transect in Fig. 7e shows a 150-m deep polluted layer near the surface that is slightly slanted. Weak upslope winds may have caused this asymmetry. Apart from this polluted near-surface layer the valley atmosphere is clean and does not exhibit elevated pollution layers. The along-valley transect in Fig. 7f reveals strong horizontal aerosol gradients, i.e. a non-homogeneous distribution of aerosols in the polluted layer. For example, over a relatively short distance of $2 \mathrm{~km}$ (between $x=8$ and $10 \mathrm{~km}$ ) near the base station (see blue dashed line) several backscatter maxima and minima can be identified. In agreement with the lidar transect in Fig. 7e, the Metair DIMO at about 1200 UTC shows a relatively shallow polluted layer with only marginal signs of pollution transport by slope winds above the south-east-exposed slope (Fig. 8c-d). In the shown transect the flow is downvalley (Figs. 9b and $3 \mathrm{~b}-\mathrm{c}$ ), and in a transect conducted about half an hour later (not shown) the first sign of a flow reversal is detected in the lowest flight leg at $\approx 150 \mathrm{~m}$ a.g.l.

\subsubsection{Temporal Evolution of Concentrations}

The mentioned transition to upvalley winds, with significant speeds above $1 \mathrm{~m} \mathrm{~s}^{-1}$, is documented by tethered balloon soundings in Fig. 5d and occurs at 1230 UTC. This flow reversal causes a sudden increase in PM10 concentrations as shown in Fig. 5e-f. The increase apparent in Fig. 5f is about $40 \%$ averaged over the shown depth, and the advection of pollutants along the valley is responsible for this change. Along-valley gradients in concentrations, as shown in Sect. 3.4.3, are a necessary precondition for this advection. A closer inspection and comparison of Fig. 5d and e shows more than one upvalley (downvalley) wind period/region that is associated with high (low) concentrations of PM10. The phenomenon may be explained as a back-and-forth transport of pollutants due to multiple flow reversals, implying a recirculation of polluted air by changing valley winds. The transport is not vertically constant, since wind speeds and gradients are neither constant, producing a complicated transient vertical structure where concentrations at one instant (e.g., 1200 UTC) are higher at the surface than further aloft and vice versa at a second instant (e.g., 1100 or 1300 UTC; see Fig. 5e).

\subsection{Transport by Slope Winds (Case 2)}

01 February 2006 is a second case that demonstrates the importance of slope winds for the transport of pollutants. The event has been examined in detail by Harnisch et al. (2009). Herein, we will focus on a comparison to the 24 January 2006 (Sect. 3.3) by emphasising differences in the flow and pollution patterns. 


\subsubsection{Mesoscale Background}

On 01 February 2006, a high-pressure system located over central Europe was responsible for fair-weather conditions in the Alps. Winds at crest level were generally weak (e.g., $\leq 5 \mathrm{~m} \mathrm{~s}^{-1}$ at Patscherkofel). An undisturbed thermally-driven circulation became established in the Inn Valley with a $800-\mathrm{m}$ deep downvalley flow in the morning, captured by a radiosonde ascent at about 0900 UTC (Harnisch et al. 2009), and a 400-m deep upvalley flow in the afternoon, observed by the Metair DIMO at about 1500 UTC (Fig. 3b-c). The static stability in the lower part of the valley atmosphere was much higher $\left(\partial \theta / \partial z \approx 0.016 \mathrm{Km}^{-1}\right)$ than on 24 January 2006 (cf. Fig. 3a). However, the stratification profile, with a strongly stable layer up to about $1.6 \mathrm{~km}$ m.s.l., was similar to the profile on 25 January.

\subsubsection{Diurnal Pattern at the Surface}

Apart from thin cirrus clouds, which disturbed the cycle of global radiation around noon, solar irradiation was strong enough to induce a pronounced diurnal cycle in near-surface temperatures (Fig. 4d). Associated with this heating of the valley atmosphere is a transition to upvalley winds at around 1100 UTC. On average, pollution concentrations were high, e.g., $58 \mu \mathrm{g} \mathrm{m}^{-3}$ for the daily mean value of PM10. Before the wind reversal, the concentrations of $\mathrm{NO}_{x}$ and PM10 followed the typical cycle with a maximum in the morning and a decrease during the afternoon (Fig. 4d). The minimum in PM10 shortly before 1100 UTC is unrealistically low and presumably affected by a measurement error. Nevertheless, a clear minimum is also found at this time in the concentrations of $\mathrm{NO}_{x}$ (Fig. 4d). With the reversal of the valley winds concentrations rapidly increased, leading to a secondary maximum around noon for PM10 and early afternoon for $\mathrm{NO}_{x}$, respectively. We attribute this atypical behaviour to the advection of pollutants by upvalley winds. Such a flow reversal and secondary maximum in concentrations was not observed on 24 January.

\subsubsection{Spatial Distribution of Pollutants}

The PM10 profiles at 1400 UTC in Fig. 6d depict two features: the concentrations in the middle of the valley are not as homogeneous in the vertical direction as on 24 January but decrease with altitude. This structure can be attributed to higher stability near the surface on 01 February (see Sect. 3.5.1), which also causes a lower sodar-derived mixing-layer height of $\approx 100 \mathrm{~m}$ (Schäfer et al. 2008; their Fig. 7). In analogy to the 24 January, however, an asymmetry in the cross-valley direction can be identified with higher concentrations along the south-east facing slope.

This asymmetry is also documented in the lidar cross-section at about 1400 UTC shown in Fig. 7g. Consistent with the PM10 soundings of the lowest $200 \mathrm{~m}$ a.g.l., highest backscatter intensities occur along the south-east-exposed slope, followed by the north-west-exposed slope and the middle of the valley. Analogous to the case on 24 January, slope winds most likely caused an upward transport of aerosols and the formation of elevated aerosol layers, while most of the aerosols remain inside the valley below $\approx 1.3 \mathrm{~km}$ m.s.l. While on $24 \mathrm{Jan}-$ uary the most pronounced aerosol layer forms at the bottom of a relatively deep inversion (Sect. 3.3.3), the two elevated aerosol layers in Fig. $7 \mathrm{~g}$ coincide with two shallow inversion layers embedded in the very stable valley atmosphere (Harnisch et al. 2009). The asymmetry in the lidar transect is supported by airborne in situ measurements of aerosols and $\mathrm{NO}_{2}$ (Fig. 8e-f). While on 01 February aircraft data reveal weak downvalley winds above a 
shallow layer of upvalley flow (Fig. 9c), winds on 24 January were downvalley at all levels (Fig. 9a) as a result of a compensation flow (see Sect.3.3.2).

Figure $7 \mathrm{~h}$ shows the lidar transect conducted along the valley at 1430 UTC. Vertical aerosol gradients in the lowest $400 \mathrm{~m}$ AGL are greater than on 24 January (Fig. 7d), in agreement with the PM10 profiles shown in Fig. 6 b,d. The elevated aerosol layer at $\approx 1.2 \mathrm{~km} \mathrm{~m}$.s.l. is less pronounced than on 24 January, which may be a sign of weaker cross-valley transport. Close to the ground, the lidar detects shallow aerosol maxima, e.g., in the vicinity of the base station, with a horizontal width of a few kilometres. These maxima might be related to local pollution sources, such as towns, and imply strong horizontal aerosol gradients. The location of these pollution maxima and the associated gradients may be different at the time of the flow reversal (about 1100 UTC) for which we do not have lidar data available. Nevertheless, the existence of these gradients supports the idea of the advection of pollutants at the time of the flow reversal discussed in Sect.3.5.2. However, as a result of the considerable variability in concentrations along the valley close to the ground, the magnitude and even sign of the advection depends on the exact location.

\section{Discussion}

Figure 10 and Table 1 summarise three types of air pollution transport observed and analysed in this wintertime study. Type one (Fig. 10a) describes the transport of pollutants by a density current, characterised by an air mass difference along the valley with cooler and nearly stagnant air in the lower Inn Valley near the surface. Downvalley flow prevails in the upper part of the Inn Valley. This westerly flow is dynamically enhanced by shallow foehn winds that are deflected from the Wipp Valley into the Inn Valley. This intensified flow is associated with turbulent mixing and low pollution concentrations above the surface inversion. While concentrations are moderate within the surface inversion in the upper Inn Valley, they are high within the cooler near-surface layer in the lower Inn Valley. In the afternoon, the cooler air mass starts to propagate upvalley, in analogy to a density current, causing a low-level flow reversal and the advection of pollutants. This type was observed on 16 January 2006 (see Sect. 3.2).

Type two (Fig. 10b) illustrates the back-and-forth transport of pollutants by valley winds, characterised by weak radiative heating due to the occurrence of clouds and therefore high static stability and shallow pollution layers close to the ground. Apart from the lowest hectometre(s), moderate to weak downvalley winds prevail throughout the day as a result of reduced solar heating and a weak "sandwich" foehn in the Wipp Valley. The near-surface layer, however, is characterised by more than one period of upvalley winds and horizontally non-homogeneous concentrations of pollutants. Isolated regions of high pollution concentrations are found in this layer with a typical width of a few kilometres and less; their locations are not fixed in time. Multiple flow reversals in this layer cause a back-and-forth transport of polluted air that provokes transient peaks in the time series of pollutant concentrations at a specific location. This type occurred on 25 January 2006 (see Sect. 3.4).

Type three (Fig. 10c) describes the transport of pollutants by upslope winds, characterised by weak dynamical forcing, i.e. weak synoptic and mesoscale pressure gradients and winds, and is therefore dominated by thermal forcing due to solar irradiation. A broken snow cover along the valley slopes with treetops free of snow implies a relatively low albedo compared to the valley floor and mountain summits. Consequently, surface-layer heating above the sun-exposed slope is strong enough to induce upslope winds. On the opposite valley side upslope winds are either weak or katabatic downslope winds prevail throughout the day. The resulting one-sided thermal circulation leads to an asymmetric distribution of pollutant 


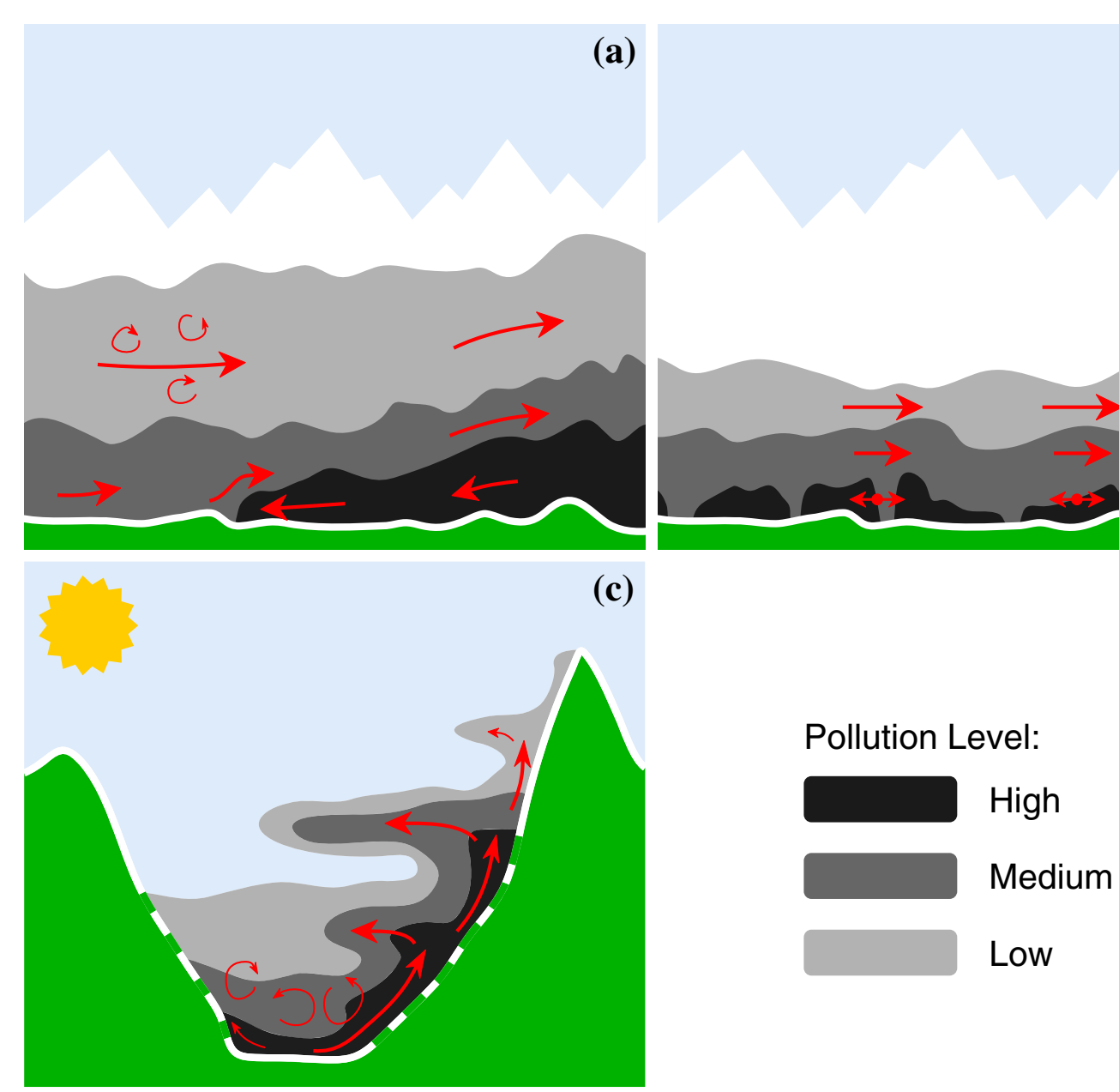

Fig. 10 Schematic of three types of air pollution transport observed in an Alpine valley in winter: a transport by a density current, $\mathbf{b}$ back-and-forth transport by valley winds, $\mathbf{c}$ transport by upslope winds. Three selected pollution layers are grey shaded. Arrows indicate mean flow and turbulent eddies. Downvalley winds in (a-b) are blowing from left to right. A white solid (dashed) line indicates a closed (broken) snow cover

concentrations. Cross-valley flow and upslope winds transport pollutants from the sources at the valley floor to higher altitudes, and near the elevated inversion layers or discontinuities in one or more surface properties (e.g., albedo or terrain steepness) the flow separates from the slope to form elevated pollution layers. Such intrusions of air into the environment as a result of inhomogeneities in ambient stability and surface properties are supported by other studies (e.g., Vergeiner and Dreiseitl 1987; Shapiro and Fedorovich 2007). Detrainment of pollutants is presumably responsible for making the pollution "channel" one order of magnitude thicker than the relatively thin slope wind layer. The intensity of turbulent mixing and therefore the daytime reduction of strong vertical pollution gradients in the lowest few hectometres above the valley floor depends on the initial (morning) low-level stability. This type of transport was found on 24 January and 01 February 2006 (see Sects. 3.3 and 3.5), though on 01 February, however, the transport is a hybrid case since it has type three as well as type two characteristics (see Sect.3.5.3).

\section{Conclusions}

Airborne and ground-based observations collected in the wintertime atmosphere of an Alpine valley have been analysed in order to elucidate the spatial distribution of air pollutants and 
dispersion processes. Based on four events we identified three different types of mechanisms for air pollution transport (Sect. 4). These are transport by a density current (type one), backand-forth transport by valley winds (type two), and transport by upslope winds (type three). Additional types are likely to exist, but have not been identified in our limited dataset. A mixture of several types may occur in reality. The following conclusions are drawn from our study:

(i) Horizontal advection of pollutants, e.g., associated with a wind reversal, may lead to a sudden decrease or increase in the concentration of pollutants. Such a change could be misinterpreted by attributing the behaviour to a local mechanism alone, such as enhanced or reduced mixing caused by a decrease or increase in local stability.

(ii) Populated areas located on valley slopes relatively far from the main emission sources at the valley floor may be affected by the vertical transport of pollutants. Even in wintertime, upslope winds may be strong enough to transport pollutants above the low-level inversion.

(iii) The geometry and the surface conditions of the valley greatly influence the dispersion of pollutants. Asymmetric transport by slope winds may occur due to asymmetries in solar heating as a result of differences in the orientation of the two slopes. The snow condition influences albedo and therefore determines the extent to which upslope winds can develop.

(iv) The observed spatial inhomogeneity in the horizontal distribution of pollutants suggest that single vertical profiles or point measurements at the surface are hardly representative of a larger valley domain. Especially in situations where the stability close to the ground is very high, sharp horizontal gradients in pollution concentration may exist with several concentration maxima and minima within a few kilometres. Therefore, the horizontal radius of representativity of such measurements is strongly case dependent and may be smaller than $1 \mathrm{~km}$. Further, the locations of concentration maxima are not steady and therefore not always linked to the positions of local emission sources.

(v) The demonstrated impact of local winds on air pollution concentration questions the use of the single-column mixing-layer concept (see e.g., Seibert et al. 2000a) often applied even in complex terrain. The assumption is made that pollutants are mixed or trapped in a single vertical column, and often the mixing height is estimated from thermodynamic parameters derived from a vertical sounding. The effects of cross-valley and along-valley transport and redistribution are usually not taken into account. Such processes, however, may lead to situations, e.g., elevated pollution layers, in which thermodynamic parameters are not well correlated with the concentration of pollutants. In this context, vertically pointing remote sensing instruments, such as sodars and ceilometers, are promising and appear to capture such layers (e.g., Emeis et al. 2007) but are still restricted to one spatial dimension. Aircraft measurements, as used in this study, provide three-dimensional data but are not appropriate for continuous observations over a longer period. Ground-based scanning wind and aerosol lidars (e.g., Darby et al. 2006; Spuler and Mayor 2005) would fill this gap, and would be of great value in future air quality studies over Alpine terrain.

Acknowledgements We would like to thank Axel Kreuter and Esther Grießer from the University of Innsbruck for their support in conducting the measurements and the DLR Flight Facility for planning and carrying out the Cessna aircraft missions. The ASFINAG VTG and the Tiroler Landesregierung are acknowledged for providing traffic flow data. We are indebted to the national weather service ZAMG for access to their AWS database. This work was funded by the European Fleet for Airborne Research (EUFAR), the Tiroler Wissenschaftsfonds (TWF), the University of Innsbruck, as well as the European Union through the INTERREG IIIB Alpine Space Programme. 


\section{References}

Bader DC, Whiteman CD (1989) Numerical simulation of cross-valley plume dispersion during the morning transition period. J Appl Meteorol 28:652-664

Banta RM, Shepson PB, Bottenheim JW, Anlauf KG, Wiebe HA, Gallant A, Biesenthal T, Olivier LD, Zhu CJ, McKendry IG, Steyn DG (1997) Nocturnal cleansing flows in a tributary valley. Atmos Environ 31:2147-2162

Beauchamp J, Wisthaler A, Grabmer W, Neuner C, Weber A, Hansel A (2004) Short-term measurements of $\mathrm{CO}, \mathrm{NO}, \mathrm{NO} 2$, organic compounds and PM10 at a motorway location in an Austrian valley. Atmos Environ 38:2511-2522

Carnuth W, Trickl T (2000) Transport studies with the IFU three-wavelength aerosol lidar during the VOTALP Mesoclina experiment. Atmos Environ 34:1425-1434

Chazette P, Couvert P, Randriamiarisoa H, Sanak J, Bonsang B, Moral P, Berthier S, Salanave S, Toussaint F (2005) Three-dimensional survey of pollution during winter in French Alps valleys. Atmos Environ 39:1035-1047

Darby LS, Allwine KJ, Banta RM (2006) Nocturnal low-level jet in a mountain basin complex. Part II: transport and diffusion of tracer under stable conditions. J Appl Meteorol Climatol 45:740-753

De Wekker SFJ, Steyn DG, Nyeki S (2004) A comparison of aerosol-layer and convective boundary-layer structure over a mountain range during STAAARTE '97. Boundary-Layer Meteorol 113:249-271

Emeis S, Jahn C, Münkel C, Münsterer C, Schäfer K (2007) Multiple atmospheric layering and mixing-layer height in the Inn valley observed by remote sensing. Meteorol Z 16:415-424

Fast JD, Allwine KJ, Dietz RN, Clawson KL, Torcolini JC (2006) Dispersion of perfluorocarbon tracers within the Salt Lake Valley during VTMX 2000. J Appl Meteorol Climatol 45:793-812

Furger M, Dommen J, Graber WK, Poggio L, Prévôt ASH, Emeis S, Grell G, Trickl T, Gomiscek B, Neininger B, Wotawa G (2000) The VOTALP Mesolcina Valley campaign 1996-concept, background and some highlights. Atmos Environ 34:1395-1412

Gohm A, Zängl G, Mayr GJ (2004) South foehn in the Wipp Valley on 24 October 1999 (MAP IOP 10): verification of high-resolution numerical simulations with observations. Mon Weather Rev 132:78-102

Hanna SR, Strimaitis DG (1990) Rugged terrain effects on diffusion. In: Blumen W (ed) Atmospheric processes over complex terrain, meteorological monographs, vol 23. American Meteorological Society, Boston, pp 109-143

Harnisch F (2007) Airborne aerosol measurements in the Inn Valley: spatial distribution of aerosols during wintertime. Diploma thesis, Institute of Meteorology and Geophysics, University of Innsbruck, Innsbruck, $112 \mathrm{pp}$

Harnisch F, Gohm A, Fix A, Schnitzhofer R, Hansel A, Neininger B (2009) Spatial distribution of aerosols in the Inn Valley atmosphere during wintertime. Meteorol Atmos Phys (in press)

Heimann D, de Franceschi M, Emeis S, Lercher P, Seibert P (eds) (2007) Air pollution, traffic noise and related health effects in the Alpine space: a guide for authorities and consulters, ALPNAP comprehensive report. Università degli Studi di Trento, Dipartimento di Ingegneria Civile e Ambientale, Trento, Italy, 335 pp. http://www.alpnap.org/results.html. Accessed 9 Jan 2009

Hennemuth B (1986) Thermal asymmetry and cross-valley circulation in a small alpine valley. BoundaryLayer Meteorol 36:371-394

Kitada T, Regmi RP (2003) Dynamics of air pollution transport in late wintertime over Kathmandu Valley, Nepal: as revealed with numerical simulation. J Appl Meteorol 42:1770-1798

Kossmann M, Corsmeier U, De Wekker SFJ, Fiedler F, Vögtlin R, Kalthoff N, Güsten H, Neininger B (1999) Observations of handover processes between the atmospheric boundary layer and the free troposphere over mountainous terrain. Contrib Atmos Phys 72:329-350

Lee SM, Fernando HJS, Princevac M, Zajic D, Sinesi M, McCulley JL, Anderson J (2003) Transport and diffusion of ozone in the nocturnal and morning planetary boundary layer of the Phoenix valley. Environ Fluid Mech 3:331-362

Martilli A, Steyn DG (2007) A numerical study of recirculation processes in the Lower Fraser Valley (British Columbia, Canada). In: Borrego C, Norman AL (eds) Air pollution modeling and its applications XVII. Springer, New York, pp 97-101

McKendry IG, Steyn DG, Lundgren J, Hoff RM, Strapp W, Anlauf K, Froude F, Martin JB, Banta RM, Olivier LD (1997) Elevated ozone layers and vertical down-mixing over the Lower Fraser Valley, BC. Atmos Environ 31:2135-2146

McKendry IG, Steyn DG, Banta RM, Strapp W, Anlauf K, Pottier J (1998) Daytime photochemical pollutant transport over a tributary valley lake in southwestern British Columbia. J Appl Meteorol 37:393-404 
Meister A, Fix A, Flentje H, Wirth M, Ehret G (2003) TropOLEX: a new tuneable airborne lidar system for the measurement of tropospheric ozone. In: Proceedings of the 6th international symposium on tropospheric profiling, Leipzig, 14-20 September 2003, pp 233-253

Molitor R, Käfer A, Thaller O, Samaras Z, Tourlou PM, Ntziachristos L (2001) Road freight transport and the environment in mountainous areas. Technical report 68, European Environment Agency. http://www. eea.europa.eu/publications/technical_report_2001_68. Accessed 9 Jan 2009

Prévôt ASH, Dommen J, Bäumle M, Furger M (2000) Diurnal variations of volatile organic compounds and local circulation systems in an Alpine valley. Atmos Environ 34:1413-1423

Reuten C, Steyn DG, Strawbridge KB, Bovis P (2005) Observations of the relation between upslope flows and the convective boundary layer in steep terrain. Boundary-Layer Meteorol 116:37-61

Reuten C, Steyn DG, Allen SE (2007) Water tank studies of atmospheric boundary layer structure and air pollution transport in upslope flow systems. J Geophys Res 112:D11114

Schäfer K, Vergeiner J, Emeis S, Wittig J, Hoffmann M, Obleitner F, Suppan P (2008) Atmospheric influences and local variability of air pollution close to a motorway in an Alpine valley during winter. Meteorol $\mathrm{Z}$ 17:297-309

Schmidli J, Poulos GS, Daniels MH, Chow FK (2009) External influences on nocturnal thermally driven flows in a deep valley. J Appl Meteorol Climatol 48:3-23

Schnitzhofer R, Beauchamp J, Dunkl J, Wisthaler A, Weber A, Hansel A (2008) Long-term measurements of $\mathrm{CO}, \mathrm{NO}, \mathrm{NO}_{2}$, benzene, toluene and $\mathrm{PM}_{10}$ at a motorway location in an Austrian valley. Atmos Environ 42:1012-1024

Seibert P, Beyrich F, Gryning SE, Joffre S, Rasmussen A, Tercier P (2000a) Review and intercomparison of operational methods for the determination of the mixing height. Atmos Environ 34:1001-1027

Seibert P, Feldmann H, Neiniger B, Bäumle M, Trickl T (2000b) South foehn and ozone in the Eastern Alps — case study and climatological aspects. Atmos Environ 34:1379-1394

Shapiro A, Fedorovich E (2007) Katabatic flow along a differentially cooled sloping surface. J Fluid Mech 571:149-175

Spuler SM, Mayor SD (2005) Scanning eye-safe elastic backscatter lidar at $1.54 \mu \mathrm{m}$. J Atmos Ocean Technol 22:696-703

Triantafyllou AG, Kassomenos PA (2002) Aspects of atmospheric flow and dispersion of air pollutants in a mountainous basin. Sci Total Environ 297:85-103

Umweltbundesamt (2004) Statuserhebung betreffend Überschreitung der IG-L-Grenzwerte für PM10 und Schwebestaub, Blei und Cadmium im Staubniederschlag im Inntal, 2002. Report prepared by order of the Tiroler Landesregierung, Umweltbundesamt GmbH, Wien, 236 pp. http://www.tirol.gv.at/uploads/ media/Stat_2002_PM10.pdf. Accessed 9 Jan 2009

Vergeiner I, Dreiseitl E (1987) Valley winds and slope winds-observations and elementary thoughts. Meteorol Atmos Phys 36:267-286

Vergeiner J, Mayr GJ (2000) Case study of the MAP-IOP "sandwich" foehn on 18th October 1999. MAP Newsl 13:36-37. http://www.map.meteoswiss.ch/map-doc/newsletter13.htm. Accessed 9 Jan 2009

Wakimoto RM, McElroy JL (1986) Lidar observation of elevated pollution layers over Los Angeles. J Clim Appl Meteorol 25:1583-1599

Weigel AP, Rotach MW (2004) Flow structure and turbulence characteristics of the daytime atmosphere in a steep and narrow Alpine valley. Q J Roy Meteorol Soc 130:2605-2627

Whiteman CD (1989) Morning transition tracer experiments in a deep narrow valley. J Appl Meteorol 28:626635

Whiteman CD (2000) Mountain meteorology: fundamentals and applications. Oxford University Press, New York, 355 pp

Wotawa G, Seibert P, Kromp-Kolb H, Hirschberg M (2000) Verkehrsbedingte Stickoxid-Belastung im Inntal: Einfluss meteorologischer und topographischer Faktoren. Final report, project no. 6983 of OeNBJubiläumsfonds, Institut für Meteorologie und Physik, Universität für Bodenkultur, Wien, 28 pp. http:// www.boku.ac.at/imp/envmet/Inntal-Bericht.pdf. Accessed 9 Jan 2009 